\title{
Decrease in SYM-H during a storm main phase without evidence of a ring current injection
}

R. E. Lopez ${ }^{1}$, W. D. Gonzalez², V. Vasyliūnas ${ }^{3}$, I. G. Richardson ${ }^{4}$, C. Cid $^{5}$, E. Echer ${ }^{2}$, G.

D. Reeves ${ }^{6}$, and Pontus C. Brandt ${ }^{7}$

${ }^{1}$ Department of Physics, University of Texas at Arlington, Arlington, TX, USA

${ }^{2}$ INPE, Sao Jose dos Campos, Brazil

${ }^{3}$ Max-Planck-Institut für Sonnensystemforschung, Göttingen, Germany

${ }^{4}$ CRESST and Department of Astronomy, University of Maryland, College Park, and NASA Goddard Space Flight Center, Greenbelt, MD, USA

${ }^{5}$ Space Research Group - Space Weather, Departamento de Física y Matemáticas, Universidad de Alcalá, Alcalá de Henares, Spain

${ }^{6}$ Los Alamos National Laboratory, MS D466, Los Alamos, NM, USA

${ }^{7}$ The Johns Hopkins Applied Physics Laboratory, Laurel, MD, USA

Corresponding Author: R. E. Lopez, Department of Physics, University of Texas at Arlington, Arlington, TX, 76019, USA (relopez@uta.edu) 


\begin{abstract}
Changes in the Dst index, or the similarly constructed high-resolution SYM-H index, are thought to indicate changes in the total energy content of the ring current. However, this is not always the case. In this paper we examine an intense (SYM-H $\sim-435 \mathrm{nT}$ ) magnetic storm that occurred on March 31, 2001. The arrival at Earth of strongly southward IMF produced an immediate negative response in the SYM-H index. While energetic particle and magnetometer data from geosynchronous orbit and inner magnetosphere energetic neutral atom imaging indicate that two substorm injections took place during the main phase, there was about one hour when the SYM-H decreased more than $200 \mathrm{nT}$ with no evidence in the data for ring current enhancement. Instead the nearEarth magnetotail exhibited a growth phase indicative of a strong, growing cross-tail current, with the large substorm expansion phase and the associated injection of energetic particles coming significantly later. Data from the DMSP spacecraft demonstrate that the polar cap flux grew rapidly in response to the strongly southward IMF. We present observations showing that the decrease in SYM-H occurred when polar cap flux was increasing and there was no evidence of injection into the ring current. Our findings strongly support the relationship between Dst and the polar cap flux proposed by theoretical studies that determined that the tail current system could be a significant contributor to Dst.
\end{abstract}

Key words:

1. Magnetic storms

2. Ring Current 
3. Substorm particle injections

4. Polar cap flux 


\subsection{Introduction}

Geomagnetic storms are defined by negative excursions of the Disturbance Storm Time (Dst) index [Gonzalez et al., 1994]. The behavior of Dst during an idealized storm is illustrated in Figure 1, with the vertical dashed lines denoting the typical phases of storm evolution. The typical storm begins with a sudden increase in Dst, called a Sudden Storm Commencement (SSC), which is generally attributed to a rise in the solar wind dynamic pressure (and corresponding magnetospheric compression) at the leading edge of the solar wind structure (frequently a shock, e.g., Gosling et al. [1967]) that will produce the storm. Shortly after the SSC, the Dst index decreases sharply. This period, until Dst reaches its maximum negative excursion, is called the Main Phase. Not all storms begin with a clear SSC, and not all storms have a clean, isolated main phase. The storm main phase can last anywhere from a couple of hours to the better part of a day. Finally, the Dst index recovers over the next day to several days during the recovery phase.

The Dst index [Sugiura, 1964; Sugiura et al, 1991] is constructed from a limited set of low-latitude magnetometer stations (four stations have been used since 1970) by subtracting the quiet-time variations in the horizontal component of the field from the observed values and averaging the disturbance values to produce a low-latitude planetary index with a 1-hour time resolution. Another index, SYM-H, is produced along the same lines as the Dst index [Iyemori, 1990], but using more stations and producing a lowlatitude planetary index with a 1-minute resolution. The Dst index is generally believed to respond primarily to the ring current, though it does respond to other current systems as well [Sugiura et al, 1991]. In particular, several studies have provided an evaluation of 
the potential contribution of the tail current system [e.g., Maltsev at al., 1996; Alexseev et al., 1996; Maltsev, 2004]. The empirical magnetic field model of Tsyganenko and Sitnov [2005] was used to analyze several magnetic storms in which the tail current provided a contribution to Dst larger than that of the ring current (both the symmetric ring current and the partial ring current).

The Burton-McPherron-Russell equation [Burton et al., 1975] provides an empirically robust relationship between the main solar wind driver (presumably the electric field) and the equatorial magnetic perturbation at the Earth's surface (Dst) produced by the ring current. The equation is

$$
\frac{D s t^{*}}{\tau}+\frac{\partial D s t^{*}}{\partial t}=\alpha V B_{s}
$$

where $\alpha$ is a measure of "geoeffectiveness" (how much output for a given input), $V$ is the solar wind speed and $B_{S}$ is the southward component of the interplanetary magnetic field (IMF) so that $V B_{S}$ is the y-component of the solar wind electric field in the frame of the Earth, and Dst* is the pressure-corrected Dst [e.g., Gonzalez et al., 1989]. The ring current decay time $(\tau)$ is often taken to be 6 hours, but it was determined empirically by O'Brien and McPherron [2000] to be a function of the solar wind driver.

The Dessler-Parker-Sckopke relationship [Dessler and Parker, 1959; Sckopke, 1966] states that the negative perturbation in the horizontal component of the equatorial magnetic field (i.e., Dst) is directly proportional to the energy content of the ring current. The Burton-McPherron-Russell equation assumes that Dst is produced by the ring current, which is composed of drifting energetic particles. These particles will be continuously 
lost by processes (e.g., charge exchange) that would produce an exponential decay in the ring current energy content. Any deviation from an exponential decay must therefore represent an energy input into the ring current, and some process would have to drive that energy input. The right hand side of the equation (often referred to as the ring current injection rate) is just the deviation from exponential decay of the Dst index and so represents energy that must be injected into the ring current by the transport of plasma energy into the inner magnetosphere. That driver, the ultimate source of the energy that accelerates particles and transports them into the inner magnetosphere, is presumed in Equation 1 to be the solar wind electric field (in the magnetospheric reference frame). In the basic form of the Burton-McPherron-Russell equation, the dependence of the merging interaction on the orientation of the IMF is expressed by a simple rectifying function (only the southward component contributes).

The assumption that magnetospheric convection is directly proportional to the solar wind electric field (when the IMF is southward) is generally a reasonable assumption. However, when the IMF magnetic field is large, the linear relationship between the dayside merging rate and solar wind parameters breaks down. The transpolar potential (which is a broad measure of magnetic merging with the solar wind) becomes saturated and no longer responds to increases in the solar wind electric field [e.g., Russell et al., 2001; Siscoe et al., 2002; Lopez et al., 2010]. However, the saturation of the transpolar potential does not affect the relationship between Dst (or SYM-H) and $V B_{s}$ in the solar wind [Russell et al., 2001; Lopez et al., 2009]. The relationship persists for a wide range of $V B_{s}$ and represents a real increase in the rate of injection into the ring current, even 
though global convection (as measured by the transpolar potential) has become saturated [Lopez et al., 2009]. This means that the relationship between the solar wind input and ring current development is more complex than had been previously suspected.

Vasyliūnas [2006b] reexamined the Burton-McPherron-Russell equation by calculating a generalized form of the Dessler-Parker-Sckopke relationship [Carovillano and Siscoe, 1973, and references therein] upon which the Burton-McPherron-Russell equation is based. This reformulation contains terms related to the currents on the magnetopause, in the ionosphere, and in the tail current system. The magnetopause current is generally taken into account by calculating Dst*, and the ionospheric term is unimportant [Vasyliūnas, 2006a]. The contribution produced by the tail current system is related to the total open flux in the magnetosphere (which we refer to as the polar cap flux), which had not been considered (as such) in most previous studies, with only a few exceptions (e.g., Siscoe and Crooker, 1974). If this case, if $Q$ represents the solar wind energy input (take to be $V B_{s}$ in equation 1), the revised "Burton-McPherron-Russell" equation is

$$
\frac{D s t^{*}}{\tau}+\frac{\partial D s t^{*}}{\partial t}=Q-k \frac{d \phi}{d t}
$$

where the new term in the right hand side of this equation is proportional to the time rate of change of the polar cap flux (f), and the constant $k$ (which has units of $\mathrm{m}^{-2}$ ) is inversely proportional to the square of distance from the Earth to the inner edge of the plasma sheet.

Maltsev et al. [1996] also discussed non-ring current contributions to Dst in terms of the polar cap flux, but the discussion was motivated from a consideration of current systems in the magnetosphere. They found that the contribution would depend inversely on the 
area of the "inner magnetosphere", the boundary for which they define as the equatorial field at the magnetopause as given by the standoff distance. That area will scale like the square of the distance to the inner edge of the plasmasheet, so for all practical purposes the formulations of Vasyliūnas [2006b] and Maltsev et al. [1996] arrive at the same result. These formulations indicate that for large changes in the polar cap flux, a large fraction of typical Dst values in storms could be the due to currents in the tail system.

It is already evident that the injection of energy into the ring current is not strictly dependent on the level of convection in the magnetosphere. What if there is no energy input from the solar wind into the ring current so that the ring current does not produce any contribution to Dst? The $Q$ in equation 2, which represents the energy input from the solar wind, would be zero and any time variation in Dst would be due to current in the tail and on the magnetopause. The revised "Burton-McPherron-Russell" equation, using the pressure-correct Dst (Dst*) to represent the magnetopause currents would be

$-k \frac{d \phi}{d t}=\frac{d D s t^{*}}{d t}$

The RHS of Equation 3 would not represent any change in the energy of the ring current since the ring current does not produce any contribution to Dst in this hypothetical case. There is no change in Dst associated with the decay of a trapped particle population, hence no need to represent any exponential decay in Dst. Whatever change is observed in Dst* would just be the contribution from the magnetotail current system since contributions from solar wind pressure variations have already been removed. 
The change in the open flux is given by the difference between the rate of dayside merging and nightside reconnection. Vasyliūnas [2006b] suggested that the dependence of the time rate of change of Dst on $V B_{s}$ could be “...completely accounted for by the magnetotail effect from the increase of the open flux as the result of dayside reconnection." In fact, the empirical magnetic field model of Tsyganenko and Sitnov [2005] shows that in storms the largest contributor to the estimated Dst is the tail current system. In this paper we examine the magnetic storm on March 31, 2001 and show that at a time that SYM-H was changing rapidly, there was no evidence of a significant injection of particles into the ring current, but that there was a rapid growth in the polar cap flux. This provides direct observational evidence for the role of the polar cap flux discussed by Maltsev et al. [1996] and Vasyliūnas [2006b].

\subsection{Overview of March 31, 2001}

Figure 2 presents an overview of OMNI solar wind and magnetometer index data associated with a geomagnetic storm on March 31, 2001, during which Dst reached -387 nT. The top seven panels show the solar wind speed, density, proton temperature, and the magnetic field intensity in GSM coordinates, all from the 1-minute OMNI database. The bottom panel shows the solar wind dynamic pressure. The remaining panels provide an overview of the magnetospheric output in terms of AE and AL, SYM-H and the pressure-corrected SYM-H* [e.g., Gonzalez et al., 1989], and ASY-H. The SYM-H, SYM-H* and ASY-H indices are used here instead of Dst to provide 1-minute resolution observations of the low latitude magnetic field deviations that are generally attributed to the ring current. The ASY-H index is a measure of the asymmetry of the SYM-H 
planetary average, and it is constructed by subtracting the planetary SYM-H response from the individual station responses, then calculating the difference between the maximum and minimum deviation at the stations. Thus if every station contributing to SYM-H has the same response, ASY-H will be zero, but if one station saw a large deviation from quiet conditions and another did not, ASY-H would be large.

At 0052 UT (indicated by the vertical green line) there was a large increase in the solar wind pressure that produced a SSC signature in SYM-H. The solar wind data show that this was associated with the passage of a fast forward shock. Because of inaccuracies in mapping solar wind observations from the ACE spacecraft to the Earth (ACE provided the OMNI observations on this day) the shock in OMNI (purple vertical line) is delayed by 9 minutes relative to the SSC at 0052 UT, which gives the actual shock arrival time at Earth. The rapid fluctuations in the solar wind parameters immediately following the shock and extending to 0113 UT are also artifacts of the mapping and are absent in the original ACE data. The arrival of the shock triggered a large substorm as seen in the AE data. ASY-H recorded an increase, presumably in part due to the day/night asymmetry in the compression of the geomagnetic field. However, since the solar wind magnetic field was northward, there was no subsequent decrease in SYM-H.

A second pressure impulse at 0250 UT produced a small positive excursion in the SYM$\mathrm{H}$ index, as one would expect during magnetospheric compression, and this was coincident with a second large event in the AE data. Both of these excursions in AE were accompanied by an increase in ASY-H, suggesting the injection of a westward partial 
ring current on the nightside magnetosphere. There were additional transient increases in the solar wind pressure just after 0400 UT and again around 0440 UT, each with its own SSC-type signature in SYM-H. However, by 0330 UT, the IMF had turned southward. The IMF then turned northward again until 0415 UT, when it went strongly southward, with the southward component reaching $\sim 40 \mathrm{nT}$. It remained mostly in that orientation until 0800 UT.

The solar wind data show that the initial southward turning occurred during passage of the sheath following the shock and ahead of the arrival of a "magnetic cloud", at $~ 0600$ UT [e.g., Wang et al., 2003; Farrugia et al., 2006], that is characterized by an enhanced magnetic field that smoothly rotates in direction suggestive of a flux rope configuration [Klein and Burlaga, 1982]. The magnetic cloud interval is shaded gray in Figure 2. Southward fields persisted during the leading half of the magnetic cloud, turning to northward in the trailing half (only partially shown in Figure 2). The solar origins of the shock and magnetic cloud have been discussed by a number of authors [e.g., Srivastava and Venkatakrishnan, 2002; Wang et al., 2003; Cane and Richardson, 2003; Manoharan et al., 2004; Zhang et al., 2007; Richardson and Cane, 2010], and Farrugia et al. [2006] made a detailed study of these interplanetary structures and the geomagnetic consequences.

The major driver of large magnetic storms is a period of strong, sustained southward IMF [e.g., Gonzalez et al., 1994]. Thus, the strong southward IMF in the sheath and leading half of the magnetic cloud drove a strong geomagnetic storm followed by a recovery as 
the magnetic field turned north in the trailing half of the magnetic cloud. A second, closely following, magnetic cloud then drove a "second dip" in Dst [e.g., Farrugia et al., 2006], but it is the first few hours of this storm that are of particular interest for the current study. The main phase of this storm was short, lasting only 4 hours, but it was quite intense, with SYM-H reaching -437 nT. Using the results of Lopez et al. [2010], we estimate that the transpolar polar potential was saturated only for two brief periods during the main phase of the storm, from 0600 UT to 0645 UT and from 0715 UT to 0745 UT. Beginning at $\sim 0450$ UT there was a large, transient excursion in $\mathrm{AL}$, suggesting that that a short-lived substorm expansion had occurred. We also note that there was a large excursion in ASY-H beginning around 0630 UT. At that time the SYM-H index leveled off before continuing to decrease after 0700 UT coincident with a large increase in the AE index. This AE event was much more sustained over time and is more characteristic of a full-blown substorm.

\subsection{Geosynchronous Magnetic Field and Energetic Particle Data}

Figure 3 presents magnetometer data in GSM coordinates from the geosynchrous satellite GOES-8, with local time LT $=\mathrm{UT}-5$. Thus in the early hours of the day, GOES-8 was in the nightside, premidnight sector. At 0050 UT the impact of the pressure increase associated with the arrival of the interplanetary shock is very evident, and it produced a spike in the magnetometer data. The 0250 UT compression by the solar wind produced a more muted signature. After 0340 UT, the geosynchronous field responded to the arrival of southward IMF by stretching and growing in magnitude. This is characteristic of the substorm growth phase [e.g., Lopez et al., 1989]. The stretching of the field was briefly 
interrupted by a small dipolarization event $\left(+\delta B_{Z}\right)$ at $0410 \mathrm{UT}$, but other than that it continued unabated until 0610 UT, when a large and sustained dipolarization began (a large positive $B_{z}$ perturbation and a reduction in the magnitude of the $B_{X}$ component). The biggest changes occurred at $0630 \mathrm{UT}$, suggesting an intensification of activity at that time.

The onset of the dipolarization event was marked by a brief but intense negative excursion in $B_{z}$. A negative $B_{z}$ at geosynchronous orbit near midnight is quite rare [e.g., Lopez et al., 1989], and the evolution of the field strongly resembles the "explosive growth phase" discussed by Ohtani et al. [1992]. These data strongly suggest that a strong substorm erupted at $0610 \mathrm{UT}$, with a major intensification at $0630 \mathrm{UT}$. However there is no evidence of activity just before $0500 \mathrm{UT}$ to correspond to the spike in AL recorded at that time, even though GOES-8 was at midnight at that time.

The magnetometer data in Figure 4 from GOES-10 (LT = UT - 9) tell a similar story. The impact of the enhanced solar wind pressure/shock at 0050 UT is evident, and GOES10 (which was near $1600 \mathrm{LT}$ ) briefly crossed the magnetopause. The $B_{z}$ of about $-20 \mathrm{nT}$ in the sheath is consistent with the $-5 \mathrm{nT} B_{z}$ in the IMF at the time and a strong compression of the IMF $B_{z}$ across the high Mach number bow shock. Around 0340 UT, GOES-10 recorded the onset of a growth phase stretching of the field into a more tail-like configuration. Since GOES-10 was near the dusk terminator at this time (1900 LT), the growth of the $B_{y}$ and $B_{x}$ components of the field together with the reduction in the $B_{z}$ component are evidence that the magnetic field was being strongly stretched radially 
outward by the stress produced by merging with the IMF and the large solar wind dynamic pressure. As in the case of GOES- 8 , this growth phase proceeds fairly uniformly, with the exception of a transient signature just after $0500 \mathrm{UT}$, which is probably associated with the transient $\mathrm{AE}$ signature around that time.

At 0630 UT, GOES-10 recorded a huge dipolarization event, with a rapid relaxation of the stretched field configuration. Like GOES-8, GOES-10 recorded the signature of an explosive growth phase [Ohtani et al., 1992] just before the main event, with a brief but noticeable negative $B_{z}$ component. There seems to have been an even earlier precursor event at $0550 \mathrm{UT}$, a small dipolarization that was quickly overwhelmed by the continuing growth phase. This resembles the "pseudobreakups" discussed by Koskinen et al. [1992], as does the activity around $0500 \mathrm{UT}$.

We now turn our attention to the geosynchronous energetic particle environment as sampled by the Los Alamos spacecraft in geosynchronous orbit $\left(6.6 R_{E}\right)$. The spinaveraged energetic proton data $(\sim 40-400 \mathrm{keV})$ from three spacecraft for the entire day of 31 March 2001 are plotted in Figure 5. The three spacecraft are LANL-01A (LT $=$ UT + 1.5), 1991-080 $(\mathrm{LT}=\mathrm{UT}+12.9)$, and by 1994-084 $(\mathrm{LT}=\mathrm{UT}+6.8)$ and the vertical aqua line marks the UT for local midnight for each spacecraft while the yellow line marks local noon. Early in the day, LANL-01A was in the night sector, and it observed a largescale decrease in the flux beginning around 0300 UT, which was punctuated by two injection signatures around 0400 UT and 0450 UT, neither of which reversed the overall trend. The two other spacecraft also observed an extended reduction in the energetic 
proton flux, consistent with a stretching of the geosynchronous magnetic field. However, at 0630 UT, satellite 1991-080 (then at $\sim 1930$ LT) observed a large energy-dispersed injection, consistent with protons drifting from an injection that occurred earlier, closer to midnight, and at $0640 \mathrm{UT}$, LANL-01A recorded a large proton injection. Later in the day, particularly in the afternoon, there appear to have been a series of quasi-periodic, largescale particle injections, along the lines of what have been previously described as "sawtooth substorms" [e.g., Henderson et al., 2006]. In fact, the 0630 UT event can be considered the first "tooth" in this series of events that continued throughout the day.

Figure 6 contains the spin-averaged energetic electron data $(50-315 \mathrm{keV})$ for the three spacecraft from 0000 UT to 0600 UT. The colored lines correspond to six nested energy channels with approximate lower thresholds of $30,45,65,95,140$, and $200 \mathrm{keV}$, with an upper threshold of $300 \mathrm{keV}$ for each channel. The SSC at $0050 \mathrm{UT}$ is very evident. The spacecraft on the dayside (1991-080 and 1994-084) both crossed into the magnetosheath (as did GOES-10) while LANL-01A observed a particle injection associated with the substorm seen in the AE data. The second pressure increase, at $0300 \mathrm{UT}$, also pushed the magnetopause inward, causing 1994-084 to again enter the magnetosheath and remain there until after 0600 UT due to the sustained high pressure, while LANL-01A recorded and increase in flux. It is also interesting that 1991-080 observed intense dropouts as the overall fluxes decreased. These likely were encounters with the lobes - which has been seen in geosynchronous data before during intense stretching events. 
Figure 7 presents the spin-averaged energetic proton data $(40-400 \mathrm{keV}$ nested energy channels with the lower energy threshold that vary from satellite to satellite) for the three spacecraft from $0000 \mathrm{UT}$ to $0600 \mathrm{UT}$. Just after $0340 \mathrm{UT}$, the energetic proton and electron fluxes at LANL-01A began to decrease. This is the signature of the substorm growth phase, even though LANL-01A was in the very late post midnight sector. However, as seen in Figure 4, a growth phase signature beginning at 0340 UT was seen near the dusk as well by GOES-10 and 1991-080. This indicates that the stretching of the magnetotail was a global phenomenon across the entire nightside (which is characteristic of sawtooth type substorms).

As can be seen in Figure 5, the growth phase continued with some transient variations in the particle flux, which did not affect the overall trend, until just about 0620 UT, when LANL 01A detected an energy-dispersed, drifting electron injection. Satellite 1991-080 $(\mathrm{LT}=\mathrm{UT}+13)$ then detected an energetic electron injection along with a proton injection at 0630 UT. The other two spacecraft also subsequently recorded proton injections. At satellite 1991-080 on the duskside, the proton fluxes at 0700 UT were higher that they had been at the start of the day, around 0200 UT. The proton flux increased until about 0720 UT, when it began to decrease. Therefore, the elevated fluxes at 1991-080 tell us that there was a large injection of energetic particles on the duskside at geosynchronous orbit. Those particles would presumably have generated a strong ring current [e.g., Daglis et al., 1999] and a corresponding signal in mid latitude ground magnetometers. By contrast, there does not seem to have been a significant enhancement of the ion population on the dawnside, especially if we compare the flux levels from 
LANL 01A at 0700 UT (0830 LT) with the fluxes seen by 1994-084 at 0200 UT (0830 LT). This is consistent with the general finding that in the early phase of a magnetic storm the ring current is asymmetric as the ions drift duskward around the Earth [Leimohn et al., 2001; Reeves et al., 2002]. This is also consistent with the ASY-H data. Inspecting Figure 2, we see that, just after 0600 UT and especially after 0630 UT, there is a strong signal of an asymmetric perturbation in the mid latitude magnetic field.

\subsection{Ground Magnetometer and Inner Magnetospheric Imaging Data}

Figures 8 and 9 present the magnetometer data from a range of mid and low latitude stations that provide a global view of the nightside sector. The magnetic latitudes and longitudes of these stations can be found in Table 1. Mid and low latitude magnetometer data are useful for substorm studies since the signature of the substorm is quite identifiable [e.g., McPherron et al, 1973] and such data can be used to provide a global context for substorm onset and evolution [e.g., Lopez et al., 1990].

Figure 8 presents the $H$ component (positive northward) from the stations arranged in order from west to east (top to bottom). The compression in the geomagnetic field produced by the $0050 \mathrm{UT} \mathrm{SSC}$ is quite visible. The solar wind pressure increase at 0300 UT also produced a signature, but one that is less noticeable. Beginning just before 0400 UT, the stations in the midnight sector (BSL and stations to the east) recorded the onset of a steady decrease in $H$, which was soon seen at all of the stations. With the exception of some small perturbations (just after 0400 UT and just before 0500 UT), the steady decrease in $H$ continued until $0610 \mathrm{UT}$, when the stations near midnight (such as DLR) 
recorded a large increase in $H$. This is the signature of substorm onset and the formation of the substorm current wedge. Moreover, at 0630 UT, there was a major intensification of the current in the current wedge, as can be seen by the additional positive perturbation in $H$. This intensification was accompanied by an expansion of activity, particularly to the east since at this time the signature of the current wedge was observed at VSS.

Figure 9 presents the $D$ component (positive eastward) from the stations, except that the values from the two southern hemisphere stations (PPT and VSS) have had the sign reversed because the signature of the substorm current wedge in the southern hemisphere in the $D$ component is reversed relative to that in the northern hemisphere. In the northern hemisphere, an eastward perturbation (a positive change in $D$ ) is the signature of a station west of the center of the current wedge, and vice versa. The sign of the $D$ perturbation after substorm onset reversed in the vicinity of DLR, indicating that that longitude was the center of the substorm current wedge.

The mid latitude data are clear - a substorm onset occurred around 0610 UT with a major expansion of activity at $0630 \mathrm{UT}$. In addition, the GOES spacecraft show evidence of a large substorm beginning around $0610 \mathrm{UT}$, with a major intensification at $0630 \mathrm{UT}$, and the LANL spacecraft particle data support this conclusion. As discussed in the overview, there was a transient excursion in AL that began at $0450 \mathrm{UT}$. This does seem to have a counterpart in the transient positive $\delta H$ signal seen in several premidnight stations (FRN to BSL) as well as in the geosynchronous data. Yet in Figure 2 there no evidence of a 
large event in $\mathrm{AE}$ at $0610 \mathrm{UT}$ or $0630 \mathrm{UT}$. The big rise in $\mathrm{AE}$, driven by a large, negative AL, occurred later, beginning a bit before $0700 \mathrm{UT}$.

The magnetometer stations that provide the data for the $\mathrm{AE}$ index are in the nominal auroral zone, roughly at $65^{\circ}$ magnetic latitude. If the polar cap is very large, then the substorm auroral electrojets, which map to closed field lines and flow equatorward of the polar cap, can be displaced to low enough latitudes that they will not register at the higher latitude AE stations. Given the large and sustained southward IMF, we would expect a very large polar cap, particularly at the end of a sustained growth phase. Figure 10 presents magnetometer data from the station at Ottawa (magnetic latitude $\left.=55.18^{\circ}\right)$. These data show that a $1200 \mathrm{nT}$, negative $H$ perturbation began at $0630 \mathrm{UT}$, indicating the sudden appearance of an enormous westward electrojet. The negative $Z$ perturbation was almost equal in size, suggesting that the center of the electrojet was just over $1^{\circ}$ (100 $\mathrm{km}$ ) north of the station, at about $56^{\circ}$ magnetic latitude. The polar cap boundary must have therefore been rather close to that latitude. Thus, there is clear corroborating evidence of a huge substorm expansion at $0630 \mathrm{UT}$, which we assume was the large intensification of substorm electrojet that began to the west of Ottawa at 0610 UT. This is also evidence that the polar cap had expanded to very low latitudes, as expected. Thus the higher latitude AE stations in the North American sector would not have picked up the signature of the electrojets until the electrojets had expanded poleward with the shrinking polar cap. That explains the delay in the AE response until 0700 UT. 
However, the behavior of SYM-H (and SYM-H*) is puzzling. At the time that the geosynchronous data indicate that there is a large injection of energetic particles into the ring current, there is no negative perturbation in SYM-H or SYM-H*. If anything, there is a transient positive spike in SYM-H and the overall growth of the negative SYM-H perturbation stops for a while, before continuing its decrease after 0700 UT until 0800, when the main phase of the storm ended and the recovery phase began. SYM-H* shows the same behavior, so the changes were not due to pressure changes in the solar wind. Moreover, until 0610 UT there was no evidence of any substorm or substantial injection of energetic particles into geosynchronous orbit. After 0610 UT we have evidence of substorm onset, and the increase in ASY-H suggest the growth of the partial ring current. The traditional view is that the partial ring current has a large effect on Dst [e.g., Liemohn et al., 2001], although other studies [Alexeev et al., 1996; Tsyganenko and Sitnov, 2005] find that the partial ring current has a very weak effect on Dst. In either case, it does not matter. The data present a comprehensive picture of the whole nearEarth magnetotail in a growth phase from 0330 UT to 0610 UT without a significant injection into the ring current (pseudobreakup-like events, such as the one at $0450 \mathrm{UT}$ notwithstanding). During that period, SYM-H and SYM-H* were steadily becoming more negative. Looking only at those data one might claim that the ring current was building up, yet the in-situ evidence indicates it was not doing so.

Energetic neutral atom observations by the HENA instrument on the IMAGE spacecraft [Mitchell et al., 2000] provide a global view of the evolution of the ring current in the inner magnetosphere [e.g., Brandt et al., 2002], where the peak of the storm-time ring 
current is located [Lui et al., 1987]. Figure 11 presents data from HENA (ions from 0-10 $\mathrm{keV}$ ) at several times throughout the period in question. Other energy channels are available, and the $0-10 \mathrm{keV}$ channel also serves as a proxy for oxygen above about 30 $\mathrm{keV}$. Comparing the first image (a) and the second (b) it seems that some energetic ions had drifted to the dayside, perhaps from an earlier injection. Image (c) shows that there had been a more substantial injection prior to $0452 \mathrm{UT}$, but that between $0452 \mathrm{UT}$ and 0600 UT (d) there was not much change in the ring current population. These HENA data are very consistent with the GOES and LANL data, and with the AE index, which show that there were limited injections (especially at 0450 UT) that did not change the overall trend of a prolonged growth phase in the tail. Thus from 0500 to 0600 UT (just before the onset of substorm activity across the nightside) there is little change in the inner magnetospheric ion flux. During this same time, SYM-H decreased by about 200 nT. Image (e) around 0700 UT shows a visibly enhanced inner magnetospheric ion flux, and other images (not shown) make it clear that the injection occurred between 0602 and 0611 UT. Thus the HENA data are consistent with the rest of the evidence that there the very large injection of energetic ions into the ring current until began just after 0600 UT. The subsequent images show the flux of the ring current intensifying (f), then becoming symmetric ( $\mathrm{g}$ and $\mathrm{h})$ as the main phase of the storm ends and the ASY-H index decreases.

\subsection{Observations of the Polar Cap Boundary}

We can estimate the amount of open flux during this event using the DMSP spacecraft, which fly in sun-synchronous orbits at about $800 \mathrm{~km}$ in altitude [e.g., Hardy et al., 1984]. The DMSP spacecraft are equipped with a variety of instrumentation collecting a range 
of data; of interest to this study are the precipitating particle data. Observations made by DMSP F13 of particle precipitation (electrons and ions from $30 \mathrm{eV}$ to $30 \mathrm{keV}$ ) are presented in Figures 12 and 13. The data are in spectrogram format; both ions (bottom panel) and electrons (top panel) are plotted. The lowest energy ions (electrons) are at the top (bottom) of the panel so that the lowest energy particles of both species are at the center of the plot.

Figure 12 shows a pass from DMSP F13 early on March 31, 2001. DMSP F-13 flies in an orbital plane approximately along the 1800 - 0600 local time meridian (other DMSP spacecraft fly along different meridians). The boundaries of the polar cap (the region of open magnetic flux) can be fairly easily determined $\left(71.9^{\circ}\right.$ on the dusk and $72.7^{\circ}$ on the dawn) by the sudden change in the particle precipitation, with the energetic ions disappearing and the electron average energy dropping below $500 \mathrm{eV}$ [e.g., Lopez et al., 2008, and references therein]. We take each point to be a point on a circle centered on the magnetic pole and integrate the dipole field in each circle to find the open flux, then average the fluxes to get an estimate of the average polar cap flux during the pass (365 $\mathrm{MWb}$ in this case). The polar cap does tend to be somewhat circular, though there can be significant deviations from this [Sotirelis et al., 1998]. While there are significant uncertainties in trying to determine the open flux at a time when it could be changing, the method described here does provide us a means to estimate the total open flux.

Figure 13 shows a DMSP F13 pass from later in the day during the main phase, but before the substorm onset at 0610 UT. The polar cap was obviously much bigger than it 
was at the beginning of the day, and using the same method as above we obtain a value of $984 \mathrm{MWb}$, very close to the figure of $1 \mathrm{GWb}$ identified by Lopez et al. [2009] as a nominal saturation value for the polar cap flux, although DeJong et al. [2007] have reported some values as large as $1.2 \mathrm{GWb}$ during sawtooth events. Using all of the DMSP spacecraft, we have made an estimate of the variation of the polar cap flux through the first 8 hours of the day. The orbital characteristics of the DMSP spacecraft in the early UT hours make it difficult to get usable observations on every pass, but a consistent picture with reasonable estimates of the size of the polar cap does emerge.

Figure 14 shows our estimate of the polar cap flux as a function of time for the March 31 , 2001 storm. The time used for the polar cap flux values estimates are the times of the center of the pass. All but two of the estimates of the polar cap flux were made using observations of two polar cap boundary crossings during a single polar cap pass by a spacecraft, with the time of the point being at the center of the pass and the flux being calculated from the circle corresponding to the average of the two boundaries. The two exceptions are at 0335 UT and 0348 UT. In the first case (0335 UT), the boundary was provided by DMSP F-15, which just barely crossed into what appears to be the polar cap for a few seconds at $79.3^{\circ}$ magnetic latitude (at $\left.1622 \mathrm{MLT}\right)$. In the second case (0348 UT), we have used the highest latitude reached by DMSP F-13 on that pass, but the spacecraft did not enter the polar cap. Thus the value of the open flux at this time is the maximum possible value. By 0415 UT, the polar cap flux had begun to grow rapidly, reaching an estimated value of about $1.1 \mathrm{GWb}$ at its peak as observed by DMSP F-14 during a pass centered at 0558 UT. This very large value of the open flux is consistent 
with the apparent "Sawtooth" nature of the event [e.g., DeJong et al., 2007] in which the tail built a very stretched configuration over time, then collapsed suddenly over a broad local time sector [e.g., Henderson et al., 2006]. The average magnetic latitude of the polar cap boundary obtained from 0558 UT pass was $58^{\circ}$, which is just poleward of the $56^{\circ}$ magnetic latitude of the 0630 UT substorm electrojet formation latitude determined from the Ottawa magnetometer data. At some point after $0630 \mathrm{UT}$, the flux dropped as the polar cap shrank and some stored flux was unloaded during the substorm. However, even by 0800 UT the polar cap flux was still rather large.

\subsection{What caused the SYM-H variations?}

The March 31, 2001 event exhibits a very interesting phenomenon. There is a two-hour period right after the arrival of very large southward IMF during which SYM-H dropped rapidly. Typically this would be viewed as evidence for a growing ring current and the injection of energy into the near Earth magnetotail in the form of energetic ions. However, there is no evidence of a large injection of energetic ions into the ring current, and from 0500 UT to 0600 UT the ring current population does not seems to have changed much. In fact, the geosynchronous evidence is that the near-Earth magnetotail was experiencing a growth phase. Only later, after 0610 UT, was there large substorm activity and the injection of ring current-enhancing energetic ions into geosynchronous orbit. Energetic neutral atom data from HENA/Image observations of the inner magnetosphere tell the same story. Until the 0610 UT substorm activity began, there was relatively little increase in the energetic ions fluxes in the inner magnetosphere, even though SYM-H decreased by $250 \mathrm{nT}$. The decrease in SYM-H was not due to changes in 
solar wind pressure since SYM-H* exhibited the same overall behavior and the solar wind pressure remained large. So if an enhanced ring current did not produce the observed signature in SYM-H, what did?

When the IMF magnetic field is large, the cross polar potential (which is a broad measure of magnetic merging with the solar wind) becomes saturated and no longer responds to increases in the solar wind electric field [e.g., Russell et al., 2001; Siscoe et al., 2002; Lopez et al., 2010]. In addition, the polar cap flux itself saturates for large southward IMF [Merkin and Goodrich, 2007; Lopez et al., 2009]. However, just after the IMF turns southward, the polar cap flux will be increasing as it approaches saturation, and it is this period that corresponds to the early part of the main phase of the storm.

As discussed in the Introduction, Vasyliunas [2006b] used a generalized form of the Dessler-Parker-Sckopke relationship and a viral theorem approach to show that the Burton-McPherron-Russell equation contains a term proportional to the total open flux in the magnetosphere. Maltsev et al. [1996] had arrived at this result by considering the effect of the tail current on Dst. If the polar cap flux grows there will be an increasingly negative contribution to Dst, a result that is independent of the exact distribution of the current [Turner et al., 2000; Maltsev and Ostapenko, 2002]. This is obvious once one considers that there is a southward perturbation at the Earth from the cross-tail current system, and the cross-tail current will grow as the lobe flux grows. An increase in the open flux will produce a growing, negative perturbation in SYM-H that has nothing to do with particle injection into the ring current. Of course the simplistic view that the cross- 
tail current contributes a certain fixed fraction of the observed Dst decrease during a storm is not correct, since the tail current system contribution to Dst derived by Maltsev et al [1996] and Vasyliūnas [2006a] depends on magnetospheric size as determined by the solar wind dynamic pressure, and the magnitude of the polar cap flux, which is variable and depends on the dayside merging and nightside reconnection rates.

The qualitative behavior of the polar cap flux is consistent with the development of the SYM-H index. After 0400 UT, the SYM-H index dropped steadily, even though there was no evidence of substorm activity and no enhancement of the energetic ions that make up the ring current. But the geomagnetic tail was stretching as the lobe flux grew, producing the observed growth phase signatures at geosynchronous orbit. Sometime around $0610 \mathrm{UT}$, and especially at $0630 \mathrm{UT}$ there was evidence of a substorm onset and the injection of energetic particles into the inner magnetosphere, as the growth in the polar cap flux halted. At first, the substorm activity was not detected in AE because the large polar cap meant that the substorm electrojets were about $10^{\circ}$ further south than normal, near the latitude of Ottawa, as seen in the magnetometer data. But as open flux was closed by reconnection in the tail, the polar cap shrank a bit. This stopped the negative march of SYM-H as the effects of the decreasing polar cap flux (which would increase SYM-H) were roughly balanced by the growth of the ring current (which would decrease SYM-H) due to an injection of substorm-accelerated particles. Our conclusion is quite similar to that of Ohtani et al. [2001] concerning the impact of substorms on the development of Dst during storms and the counterbalancing roles of the injection of particles into the ring current and the decrease in the magnitude of the tail currents. 
Even though SYM-H did not change much from 0600 UT to 0700 UT, the ASY-H index provides evidence of the effect of the energetic particles on the mid latitude magnetic field. Substorm onset at 0610 UT and the huge substorm intensification at 0630 UT produced accelerated particles at geosynchronous orbit that enhanced the ring current. Energetic neutral atom observations show that there was a substiantial injection of energetic ring current ions into the inner magnetosphere. The drift to the duskward side of the magnetosphere of these particles would have produced the observed signature in the ASY-H index. The substorm did not unload all the tail lobe flux accumulated in the preceding hours because the magnetic cloud continued to supply large amounts of newly merged flux to the tail until after $0800 \mathrm{UT}$, when the IMF turned northward. Throughout this period, from 0700 UT to $0800 \mathrm{UT}$, SYM-H continued to decrease, though at this time the decrease was due to an enhanced ring current since the polar cap flux was shrinking, not growing during this time.

Using the estimates of the open flux presented in Figure 13, we get a time rate of change for the increase in the polar cap flux of about $0.5 \mathrm{GWb} / \mathrm{hr}$. In the same time the SYM-H index dropped by $250 \mathrm{nT}$. From equation 2 (assuming that there was no ring current injection at the time) we estimate that the constant $K$ in the equation is $4 \times 10^{-16} \mathrm{~m}^{-2}$, but what is the constant $K$ ? In the derivation of Vasyliūnas [2006a], the constant is proportional to one over the square of the distance to the earthward edge of the plasma sheet. Putting in the appropriate values for the constants in $K$ gives a distance to the inner edge of the plasma sheet of about $5 R_{E}$ for the March 31, 2001 event. 
We know that the polar cap extended to very low latitudes and that the 0630 UT substorm auroral breakup and electrojet formation occurred at about $56^{\circ}$ magnetic latitude (just north of Ottawa). That latitude in a dipole field maps to $3.2 R_{E}$, and even in a stretched field it probably would not have mapped very far down the tail. The geosynchronous energetic particle data indicate that the dayside magnetopause was inside of geosynchronous orbit. Inspecting the solar wind data we find that average dynamic pressure during the March 31, 2001 event was about $30 \mathrm{nPa}$. The inner edge of the plasma sheet is typically at $8 R_{E}$ with the typical solar wind pressure of $2 \mathrm{nPa}$. If we assume Chapman-Ferraro scaling for the entire magnetosphere, all distances should be a factor of 1.6 smaller than normal during this event, which yields an inner edge of the plasma sheet at $5 R_{E}$. Thus the distance to the inner edge of the plasma sheet obtained from the Vasyliūnas [2006a] formulation is not a bad estimate, particularly given the very rough calculation that produced it.

Skoug et al. [2003] also analyzed this event and came to similar conclusions. They argued that there was no evidence for a significant injection or substorm activity to produce a strong ring current until about 0630 UT. Thus, they argued that the development of large Dst response in this storm was primarily due to tail currents. Skoug et al. [2003] did not consider the variation of the open flux as an indicator of the strength of the current system, and they used a simple model to estimate that the inner edge of the cross-tail current was at a radial distance of $1.6 R_{E}$. While our conclusions are quite similar in many respects, we believe that our estimate for the inner edge of the plasma 
sheet is more consistent with the overall scaling of the magnetosphere given the solar wind dynamic pressure and by the electrojet location north of Ottawa. Furthermore, by considering the critical role of the open flux in the magnetosphere as discussed by Maltsev et al [1996] and Vasyliūnas [2006a] one is able to get a better estimate of the actual current system in the magnetotail.

It is not a simple matter to find additional events similar to that discussed in this paper to look for similar results, in part due to the following limitations: (1) the magnetic storm has to be very large in order to have a chance to look for the desired effect with enough intensity; (2) the magnetic flux change of interest has to occur during a time interval when the magnetosphere is otherwise quiet in order to avoid ring current intensifications from a former active time, (3) the sheath region ahead of the magnetic cloud can not be very active from the beginning of the CME (with large negative Bz incursions) as is often the case during intense storms [e.g. Gonzalez et al, 1994], since otherwise intense substorm injections tend to occur very early in the main phase leading into a two-step magnetic storm intensification [Kamide et al, 1998]; and (4) the occurrence of a large solar wind pressure that results in a plasma sheet with an inner edge close to Earth in order that the change in the tail flux change has a large effect on Dst. For example, from our data set of intense storms of solar cycle 23 , we found only one more event that could have been presented in this paper as a second case (the storm of August 24, 2005, with a peak Dst of about -150 nT), but it was not as clear as the event of March 31, 2001 since it lacked most of the conditions listed above. For that event we estimate an apparent tail flux influence in Dst of only about $40 \mathrm{nT}$, as compared to the much more substantial 
effect, of about $250 \mathrm{nT}$, obtained for the March event. In addition, for the August event, it was more difficult to obtain convincing information about the lack of particle injections and polar cap boundary changes as those found for the event reported in this paper.

\subsection{Conclusions}

We have examined observations during the main phase of a magnetic storm that occurred on March 31, 2001. The storm shows evidence of a substantial growth in the negative perturbation of the SYM-H index at a time when there is no evidence of substorm activity or injection of energetic particles into the ring current. In fact, the geosynchronous data for this event indicates that the magnetotail was in a growth phase following the arrival of the strongly southward IMF. Later in the storm, there was a large substorm with multiple onsets and injections of energetic particles into geosynchronous orbit and the inner magnetosphere.

To explain the development of SYM-H in the without large injections of energetic particles into the ring current, we use arguments advanced by Maltsev et al. [1996] and Vasyliūnas [2006a,b], who pointed out that a changing amount of polar cap flux can produce a change in the surface field at the Earth that would contribute to Dst (or SYMH). Other studies [Alexeev et al., 1996; Tsganenko and Sitnov, 2005] support the view that the tail current system can be the largest contributor to Dst. The observations do indicate a rapid growth in the polar cap flux to a very large magnitude consistent with Sawtooth substorm events. 
Using the estimate of the evolution of the open flux from the observations, we show that the behavior of SYM-H is consistent with the effect of the Vasyliūnas [2006b] polar cap flux term. Given the very large solar wind dynamic pressure during this event that brought the inner edge of the plasma sheet very close to the Earth, the maximum contribution to SYM-H from the currents associated with the polar cap flux was $250 \mathrm{nT}$. For a storm with an average dynamic pressure of $2 \mathrm{nPa}$ (instead of $30 \mathrm{nPa}$ ), we estimate (using Chapman-Ferraro scaling) that the contribution to Dst would be about $100 \mathrm{nT}$, assuming that the amount of open flux was the same. Thus during magnetic storms changes in Dst in early in the main phase may not be good indicators of energy transport into the ring current because the rapid growth of the polar cap flux will have a large effect on Dst. Moreover, it is incorrect to assume that a fixed value or percentage of Dst can be attributed to the tail current system. The actual contribution will depend on many factors as discussed by Maltsev at al. [1996] and Vasyliūnas [2006a].

\section{Acknowledgments}

This paper is based upon work supported by CISM, which is funded by the STC Program of the National Science Foundation under agreement ATM-0120950, NASA grant NNX09AI63G, NSF grants ATM-0900920 and AGS1303646, Brazilian CNPq agency contract numbers 301233/2011-0 and 303329/2011-4, FAPESP agency contract number 2012/066734, grant PN-AYA2009-08662 from the Comisión Interministerial de Ciencia y Tecnología (CICYT) of Spain, and grant PPII10-0183-7802 from the Junta de Comunidades de Castilla-La Mancha of Spain. We acknowledge use of NASA/GSFC's Space Physics Data Facility's OMNIWeb and CDAWeb service, and OMNI data. We 
thank Los Alamos National Laboratory for providing the geosynchronous particle data. The DMSP particle detectors were designed by Dave Hardy of AFRL, and the data and plots were obtained from JHU/APL. The results presented in this paper rely on data collected at magnetic observatories. We thank the national institutes that support them and INTERMAGNET for promoting high standards of magnetic observatory practice (www.intermagnet.org). This work was initially discussed during the Brazil 9 Workshop on Magnetic Storms held at the Universidad de Alcalá, Alcalá, Spain in October, 2011. 


\section{References}

Asai, A., K. Shibata, T. T. Ishii, M. Oka, R. Kataoka, K. Fujiki, and N. Gopalswamy (2009), Evolution of the anemone AR NOAA 10798 and the related geo-effective flares and CMEs, J. Geophys. Res. , 114, A00A21, doi:10.1029/2008JA013291.

Alexeev, I. I., E. S. Belenkaya, V. V. Kalegaev, Y. I. Feldstein, and A. Grafe (1996), Magnetic storms and magnetotail currents, J. Geophys. Res., 101(A4), 7737-7747, doi:10.1029/95JA03509.

Borovsky, J. E., B. Lavraud, and M. M. Kuznetsova (2009), Polar cap potential saturation, dayside reconnection, and changes to the magnetosphere, J. Geophys. Res., 114, A03224, doi:10.1029/2009JA014058.

Brandt, P. C:son, D. G. Mitchell, Y. Ebihara, B. R. Sandel, E. C. Roelof, J. L. Burch, and R. Demajistre, Global IMAGE/ HENA observations of the ring current: Examples of rapid response to IMF and ring current-plasmasphere interaction, J. Geophys. Res., 107(A11), 1359, doi:10.1029/2001JA000084, 2002.

Burton, R. K., R. L. McPherron, and C. T. Russell (1975), An empirical relationship between interplanetary conditions and Dst, J. Geophys. Res., 80, 4204-4214.

Cane, H. V., and I. G. Richardson (2003), Interplanetary coronal mass ejections in the 
near-Earth solar wind during 1996-2002, J. Geophys. Res., 108, 1156, DOI: 10.1029/2002JA009817.

Carovillano, R. L., and G. L. Siscoe (1973), Energy and momentum theorems in magnetospheric dynamics. Rev. Geophys. Space Phys., 11, 289-353

Daglis, I.A., Thorne, R.M., Baumjohann, W., Orsini, S. (1999), The terrestrial ring current: origin, formation, and decay. Rev. Geophys., 37 (4), 407-438.

DeJong, A. D., Cai, X., Clauer, R. C., and Spann, J. F. (2007), Aurora and open magnetic flux during isolated substorms, sawteeth, and SMC events, Ann. Geophys., 25, 18651876, doi:10.5194/angeo-25-1865-2007.

Dessler, A. J., and E. N. Parker (1959), Hydromagnetic theory of geomagnetic storms, J. Geophys. Res., 24, 2239- 2252.

Farrugia, C. J., V. K. Jordanova, M. F. Thomsen, G. Lu, S. W. H. Cowley, and K. W. Ogilvie (2006), A two-ejecta event associated with a two-step geomagnetic storm, J. Geophys. Res., 111, A11104, doi:10.1029/2006JA011893.

Gonzalez, W. D., B. T. Tsurutani, A. L. C. Gonzalez, E. J. Smith, F. Tang, and S.-I. Akasofu (1989), Solar wind-magnetosphere coupling during intense magnetic storms (1978-1979), J. Geophys. Res., 94(A7), 8835-8851, doi:10.1029/JA094iA07p08835. 
Gonzalez, W. D., J. A. Joselyn, Y. Kamide, H. W. Kroehl, G. Rostoker, B. T. Tsurutani, and V. M. Vasyliunas (1994), What is a geomagnetic storm?, J. Geophys. Res., 99, 5771.

Gosling, J. T., J. R. Asbridge, S. J. Bame, A. H. Hundhausen, and I. B. Strong (1967), Discontinuities in the solar wind associated with sudden geomagnetic impulses and sudden commencements, J. Geophys. Res., 72, 3357.

Hardy, D. A., L. K. Schmitt, M. S. Gussenhoven, F. I. Marshall, H. C. Yeh, T. L. Shumaker, A. Hube, J. Pantazis (1984), Precipitating electron and ion detectors (SSJ/4) for the block 5D/flights 6-10 DMSP satellites: Calibration and data presentation, Rep. AFGL-TR-84-0317, Air Force Geophys. Lab., Hanscom Air Force Base, Mass.

Henderson, M. G., and et al. (2006), Substorms during the 10-11 August 2000 sawtooth event, J. Geophys. Res., 111, A06206, doi:10.1029/2005JA011366.

Iyemori, T., (1990), Storm-time magnetospheric currents inferred from mid-latitude geomagnetic field variations, J. Geomagn. Geoelectr., 42, 1249.

Kamide, Y., N. Yokoyama, W. Gonzalez, B. T. Tsurutani, I. A. Daglis, A. Brekke, and S. Masuda (1998), Two-step development of geomagnetic storms, J. Geophys. Res., 103(A4), 6917-6921, doi:10.1029/97JA03337. 
Klein, L.W., and L.F. Burlaga (1982), Interplanetary magnetic clouds at 1 AU, J. Geophys. Res., 87, 613.

Koskinen, H. E. J., R. E. Lopez, R. J. Pellinen, T. I. Pulkkinen, D. N. Baker, and T. Bosinger (1993), Pseudobreakup and substorm growth phase in the ionosphere and magnetosphere, J. Geophys. Res., 97, 5801-5813.

Liemohn, M.W., Kozyra, J.U., Thomsen, M.F., et al. (2001), Dominant role of the asymmetric ring current in producing the stormtime Dst*, J. Geophys. Res. 106, 10,88310,904 .

Lopez, R. E., A. T. Y. Lui, D. G. Sibeck, K. Takahashi, R. W. McEntire, L. J. Zanetti, and S. M. Krimigis (1989), On the relationship between the energetic particle morphology and the change in the magnetic field magnitude during substorms, J. Geophys. Res., 94, 17105-17119.

Lopez, R. E., H. Lühr, B. J. Anderson, P. T. Newell, and R. W. McEntire (1990), Multipoint observations of a small substorm, J. Geophys. Res., 95, 18897-18912.

Lopez, R. E., M. Wiltberger, J. G. Lyon, C. C. Goodrich, and K. Papadopoulos (1999), MHD simulations of the response of high-latitude potential patterns and polar cap boundaries to sudden southward turnings of the interplanetary magnetic field, Geophys. Res. Lett., 26, 967-970. 
Lopez, R. E., S. Hernandez, K. Hallman, R. Valenzuela, J. Seiler, P. Anderson, and M. Hairston (2008), Field-Aligned Currents in the Polar Cap during Saturation of the Polar Cap Potential, J. Atmos. Sol. Terr. Phys., 70, 555-563, doi:10.1016/j.jastp.2007.08.072.

Lopez, R. E., J. G. Lyon, E. Mitchell, R. Bruntz, V. G. Merkin, S. Brogl, F. Toffoletto, and M. Wiltberger (2009), Why doesn't the ring current injection rate saturate?, J. Geophys. Res., 114, A02204, doi:10.1029/2008JA013141.

Lopez, R. E., R. Bruntz, E. J. Mitchell, M. Wiltberger, J. G. Lyon, and V. G. Merkin (2010), The role of magnetosheath force balance in regulating the dayside reconnection potential, J. Geophys. Res., 115, A12216, doi:10.1029/2009JA014597.

Lugaz, N., C. Downs, K. Shibata, I. I. Roussev, A. Asai , and T. I. Gombosi (2011), Numerical investigation of a coronal mass ejection from an anemone active region: reconnection and deflection of the 2005 August 22 eruption, Astrophys. J., 738, 127.

Lui, A. T. Y., R. W. McEntire, and S. M. Krimigis (1987), Evolution of the ring current during two geomagnetic storms, J. Geophys. Res., 92(A7), 7459-7470, doi:10.1029/JA092iA07p07459.

Maltsev, Y. P. (2004). Points of controversy in the study of magnetic storms. Space science reviews, 110(3-4), 227-267. 
Maltsev, Y. P. and Ostapenko, A. A. (2002), Comment on "Evaluation of the tail current contribution to Dst" by N. E. Turner et al., J. Geophys. Res., 107, A1, 1010, doi:10.1029/2001JA900098.

Maltsev, Y. P., Arykov, A. A., Belova, E. G., Gvozdevsky, B. B., \& Safargaleev, V. V. (1996). Magnetic flux redistribution in the storm time magnetosphere. Journal of Geophysical Research: Space Physics (1978-2012), 101(A4), 7697-7704.

Manoharan, P. K., N. Gopalswamy, S. Yashiro, A. Lara, G. Michalek, and R. A. Howard (2004), Influence of coronal mass ejection interaction on propagation of interplanetary shocks, J. Geophys. Res., 109, A06109, doi:10.1029/2003JA010300.

McPherron, R. L., Russell, C. T., \& Aubry, M. P. (1973). Satellite studies of magnetospheric substorms on August 15, 1968: 9. Phenomenological model for substorms, J. Geophys. Res., 78(16), 3131-3149.

Merkin, V. G., and C. C. Goodrich (2007), Does the polar cap area saturate?, Geophys. Res. Lett., 34, L09107, doi:10.1029/2007GL029357.

Mitchell, D. G., et al., High-energy neutral atom (HENA) imager for the IMAGE mission, Space Sci. Rev., 91, 67st 15, 1968: 
O’Brien, T. P., and R. L. McPherron (2000), An empirical phase space analysis of ring current dynamics: Solar wind control of injection and decay, J. Geophys. Res., 105(A4), $7707-7720$.

Ohtani, S., K. Takahashi, L. J. Zanetti, T. A. Potemra, R. W. McEntire, and T. Iijima (1992), Initial signatures of magnetic field and energetic particle fluxes at tail Reconfiguration: Explosive growth phase, J. Geophys. Res., 97(A12), 19311-19324, doi:10.1029/92JA01832.

Ohtani, S., M. Nosé, G. Rostoker, H. Singer, A. T. Y. Lui, and M. Nakamura (2001), Storm-substorm relationship: Contribution of the tail current to Dst, J. Geophys. Res., 106(A10), 21199-21209, doi:10.1029/2000JA000400.

Reeves, G. D., Henderson, M. G., Skoug, R. M., Thomsen, M. F., Borovsky, J. E., Funtsen, H. O., C:Son Brandt, P., Mitchell, D. J., Jahn, J.-M., Pollock, C. J., McComas, D. J. and Mende, S. B. (2003) IMAGE, POLAR, and Geosynchronous Observations of Substorm and Ring Current Ion Injection, in Disturbances in Geospace: The StormSubstorm Relationship (eds A. S. Sharma, Y. Kamide and G. S. Lakhina), American Geophysical Union, Washington, D. C.. doi: 10.1029/142GM09.

Richardson, I.G., and H.V. Cane (2010), Near-Earth interplanetary coronal mass ejections during solar cycle 23 (1996-2009): catalog and summary of properties, Sol. Phys., 264, 189. 
Russell, C. T., J. G. Luhmann, and G. Lu (2001), Nonlinear response of the polar ionosphere to large values of the interplanetary electric field, J. Geophys. Res., 106, $18,496-18,504$.

Skoug, R. M., et al. (2003), Tail-dominated storm main phase: 31 March 2001, J. Geophys. Res., 108, 1259, doi:10.1029/2002JA009705.

Siscoe, G. L., and N. U. Crooker (1974), A theoretical relation between Dst and the solar wind merging electric field, Geophys. Res. Lett., 1, 17- 19.

Siscoe, G. L., G. M. Erickson, B. U. O. Sonnerup, N. C. Maynard, J. A. Schoendorf, K. D. Siebert, D. R. Weimer, W. W. White, and G. R. Wilson (2002), Hill model of transpolar potential saturation: Comparisons with MHD simulations, J. Geophys., Res., 107, 1075, doi:10.1029/2001JA000109.

Sckopke, N. (1966), A general relation between the energy of trapped particles and the disturbance field near the Earth, J. Geophys. Res., 71, 3125-3130.

Sotirelis, T., P. T. Newell, and C.-I. Meng (1998), Shape of the open- closed boundary of the polar cap as determined from observations of precipitating particles by up to four DMSP satellites, J. Geophys. Res., 103, 399-406. 
Srivastava, N. and P. Venkatakrishnan (2002), Relationship between CME speed and geomagnetic storm intensity, Geophys. Res. Lett., 29, 1287, 10.1029/2001GL013597.

Sugiura, M. (1964), Hourly values of equatorial Dst for IGY, in Annals of the International Geophysical Year, vol. 35, pp. 945-948, Pergamon Press, Oxford.

Sugiura, M. and T. Kamei (1991), Equatorial Dst index 1957-1986, in IAGA Bull., 40, edited by A. Berthelier and M. Menvielle, ISGI Publ. Off., Saint-Maur-des-Fosses France.

Turner, N. E., D. N. Baker, T. I. Pulkkinen, and R. L. McPherron (2000), Evaluation of the tail current contribution to Dst, J. Geophys. Res., 105(A3), 5431-5439, doi:10.1029/1999JA000248.

Alexeev, I. I., E. S. Belenkaya, V. V. Kalegaev, Y. I. Feldstein, and A. Grafe (1996), Magnetic storms and magnetotail currents, J. Geophys. Res., 101(A4), 7737-7747, doi:10.1029/95JA03509.

V.M. Vasyliūnas, V. M. (2006a), Ionospheric and boundary contributions to the DesslerParker-Sckopke formula for Dst, Ann. Geophys. 24, 1085-1097.

Vasyliūnas, V. M. (2006b), Reinterpreting the Burton-McPherron-Russell equation for predicting Dst, J. Geophys. Res., 111, A07S04, doi:10.1029/2005JA011440. 
Wang, Y. M., P. Z. Ye, and S. Wang (2003), Multiple magnetic clouds: Several examples during March - April 2001, J. Geophys. Res., 108 (A10), 1370, doi:10.1029/2003JA009850.

Zhang, J., I.G. Richardson, D.F. Webb, N. Gopalswamy, E. Huttunen, et al. (2007), Solar and interplanetary sources of major geomagnetic storms (Dst $\leq-100 \mathrm{nT}$ ) during 1996-2005, J. Geophys. Res., 112, A12105, DOI: 10.1029/2007JA012332.

Zhang, J., W. Poomvises, and I. G. Richardson (2008), Sizes and relative geoeffectiveness of interplanetary coronal mass ejections and the preceding shock sheaths during intense storms in 1996 - 2005, Geophys. Res. Lett., 35, L02109, doi:10.1029/2007GL032045. 


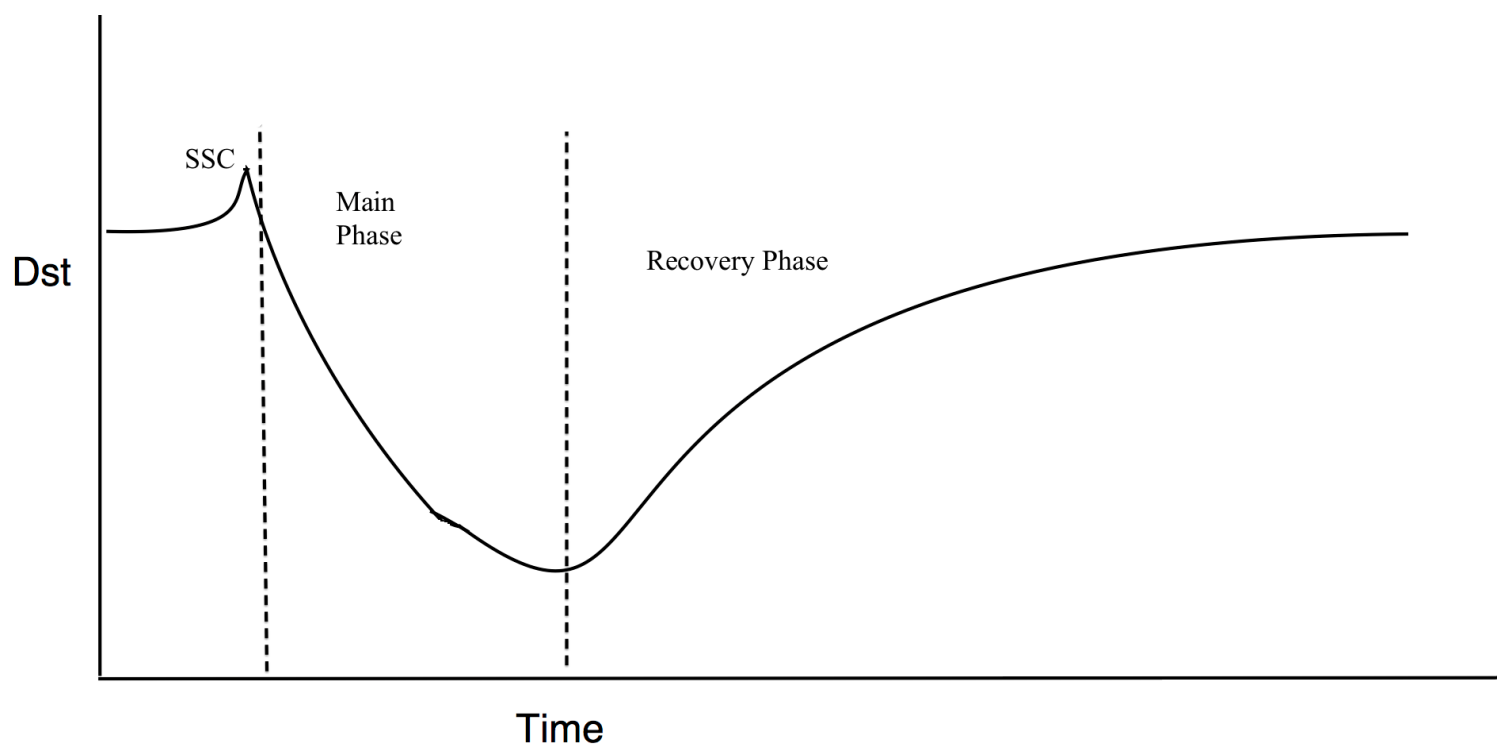

Fig. 1 - An idealized magnetic storm. 


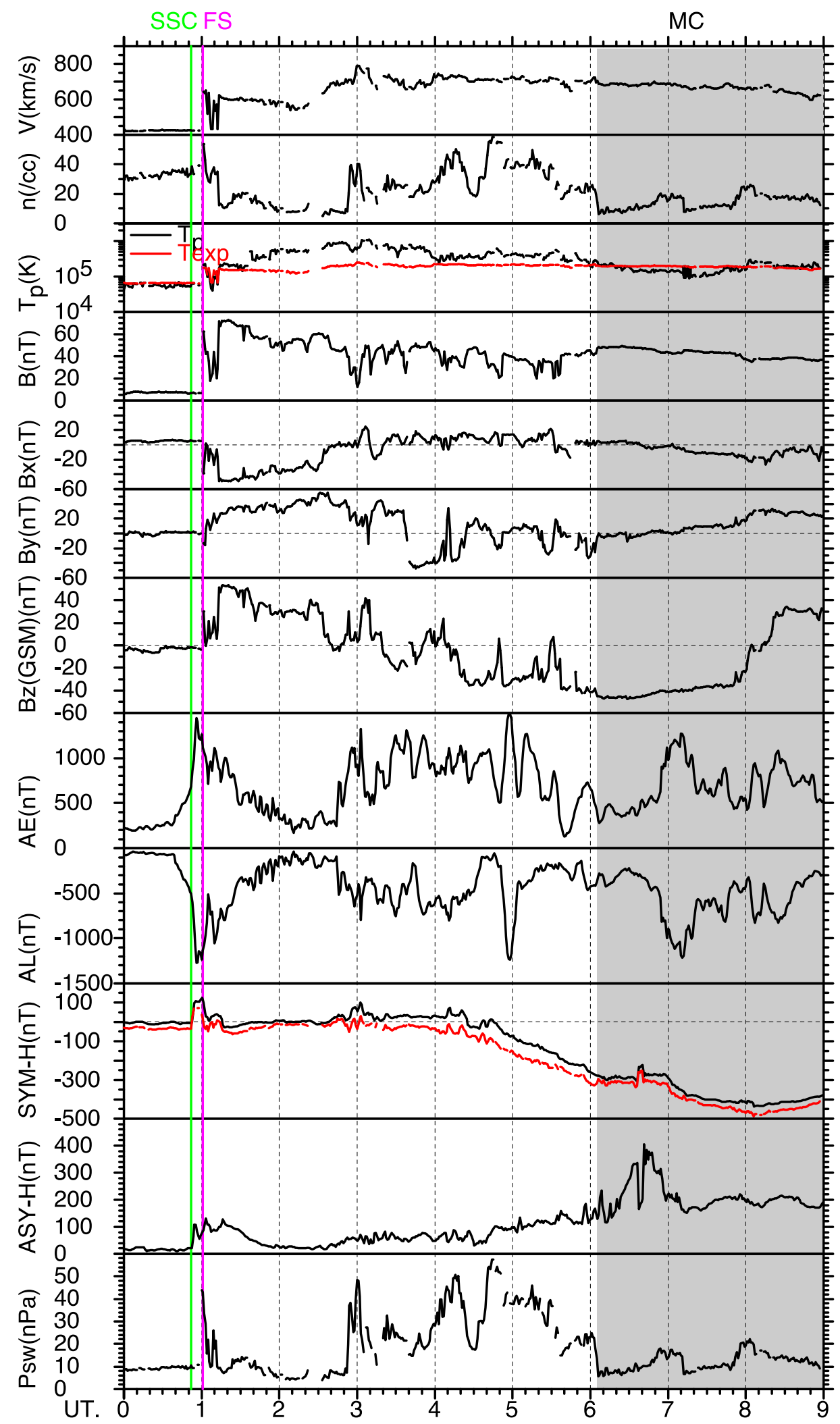

Fig. 2 - Solar Wind and magnetometer indices (from OMNI) for March 31, 2001. The red line in SYM-H is the pressure-corrected value. The sudden storm commencement (SSC), sheath (FS) and magnetic cloud (MC) are marked with vertical lines. 


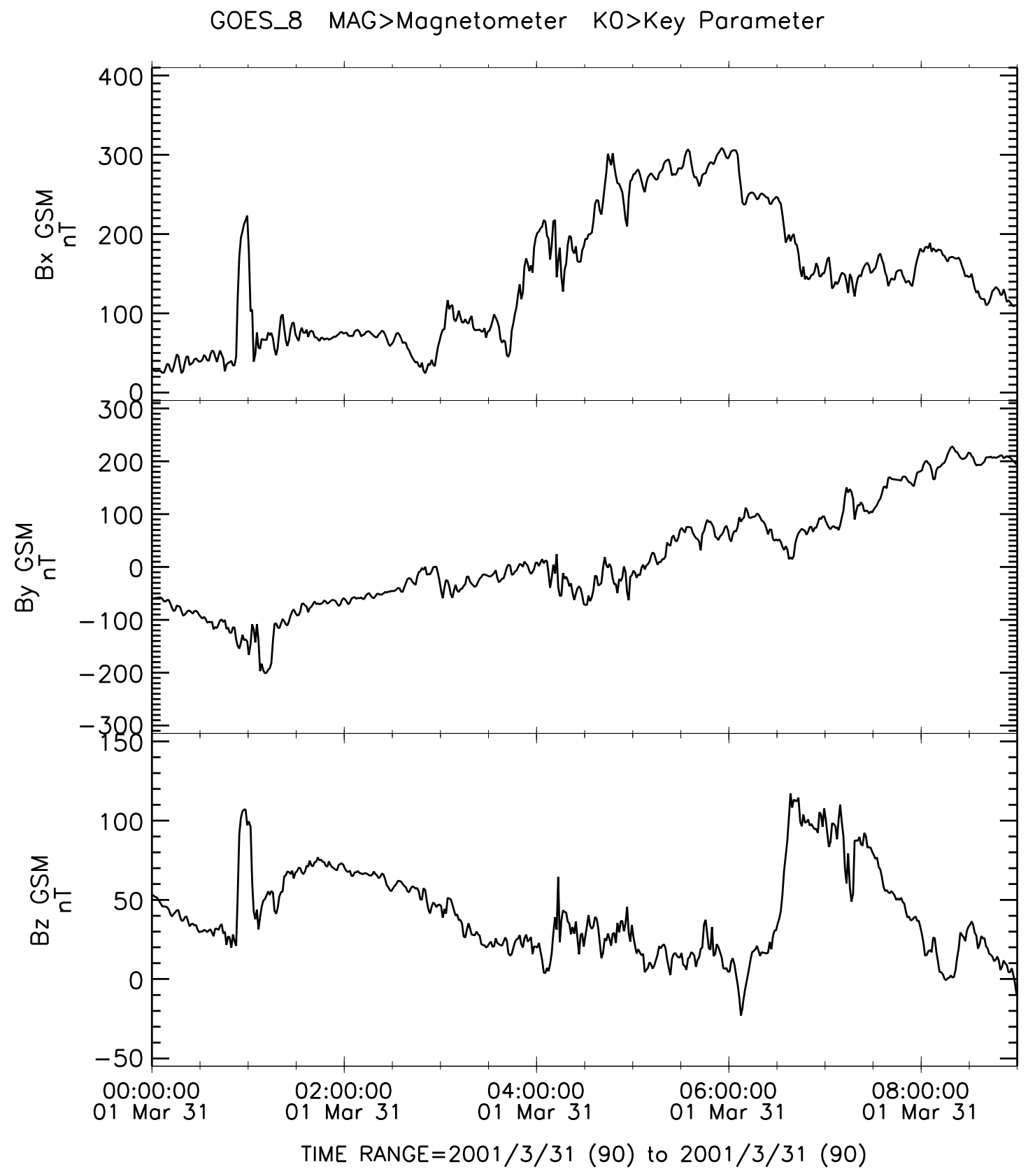

Fig. 3 - GOES-8 magnetometer data on 31 March 2001. 


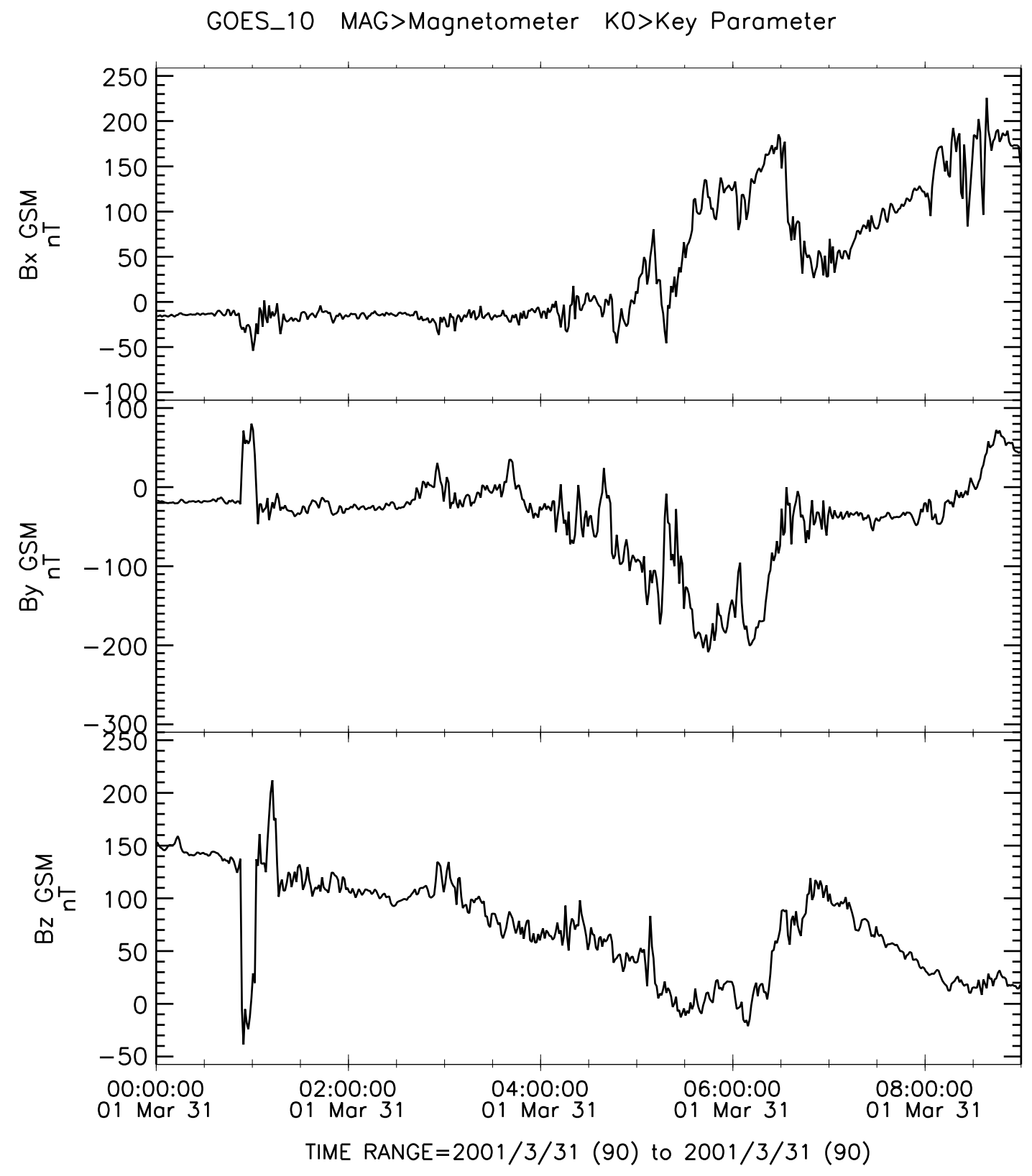

Fig. 4 - GOES-10 magnetometer data on 31 March 2001. 


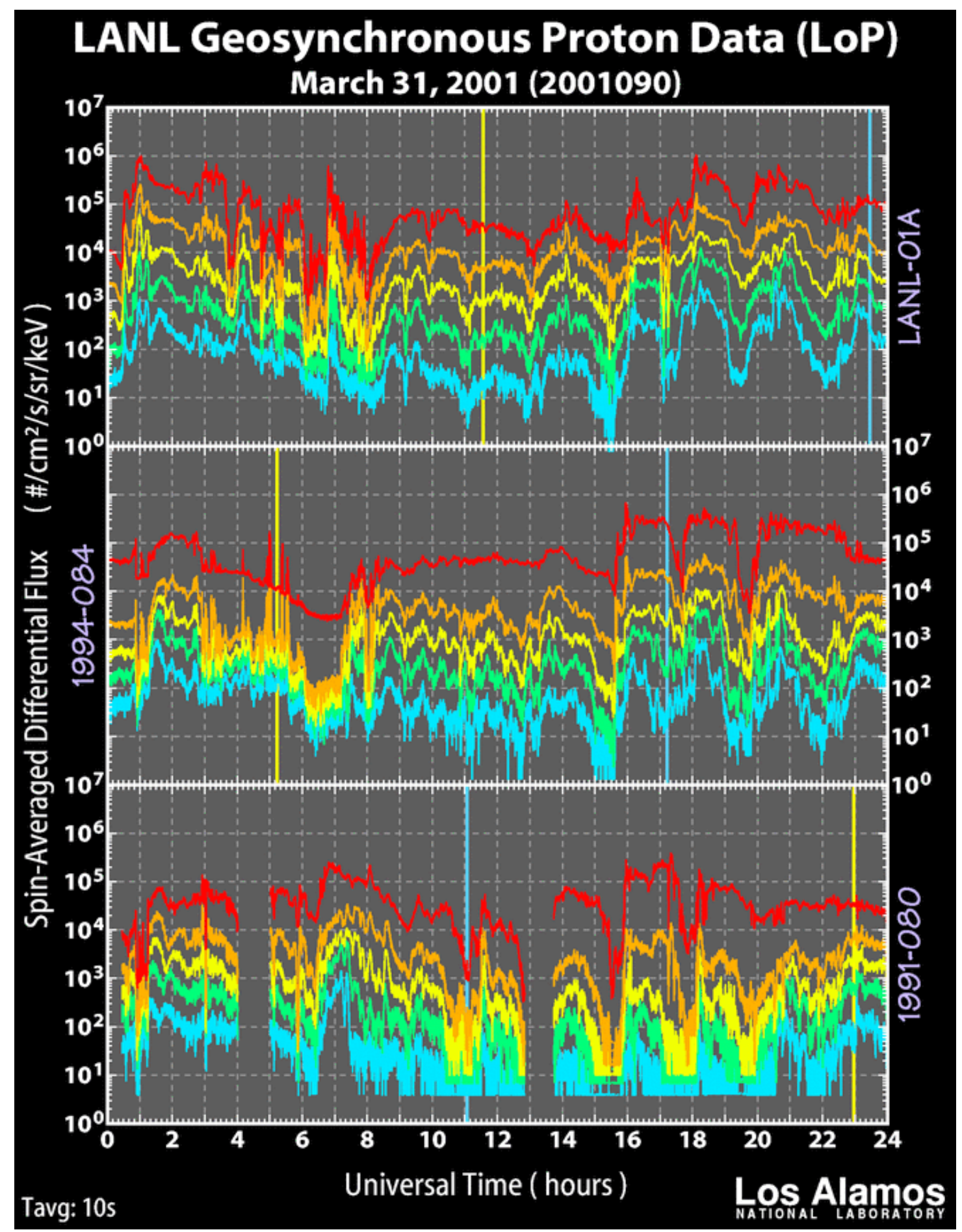

Fig. 5 - LANL Geosynchronous energetic proton data on 31 March 2001. 


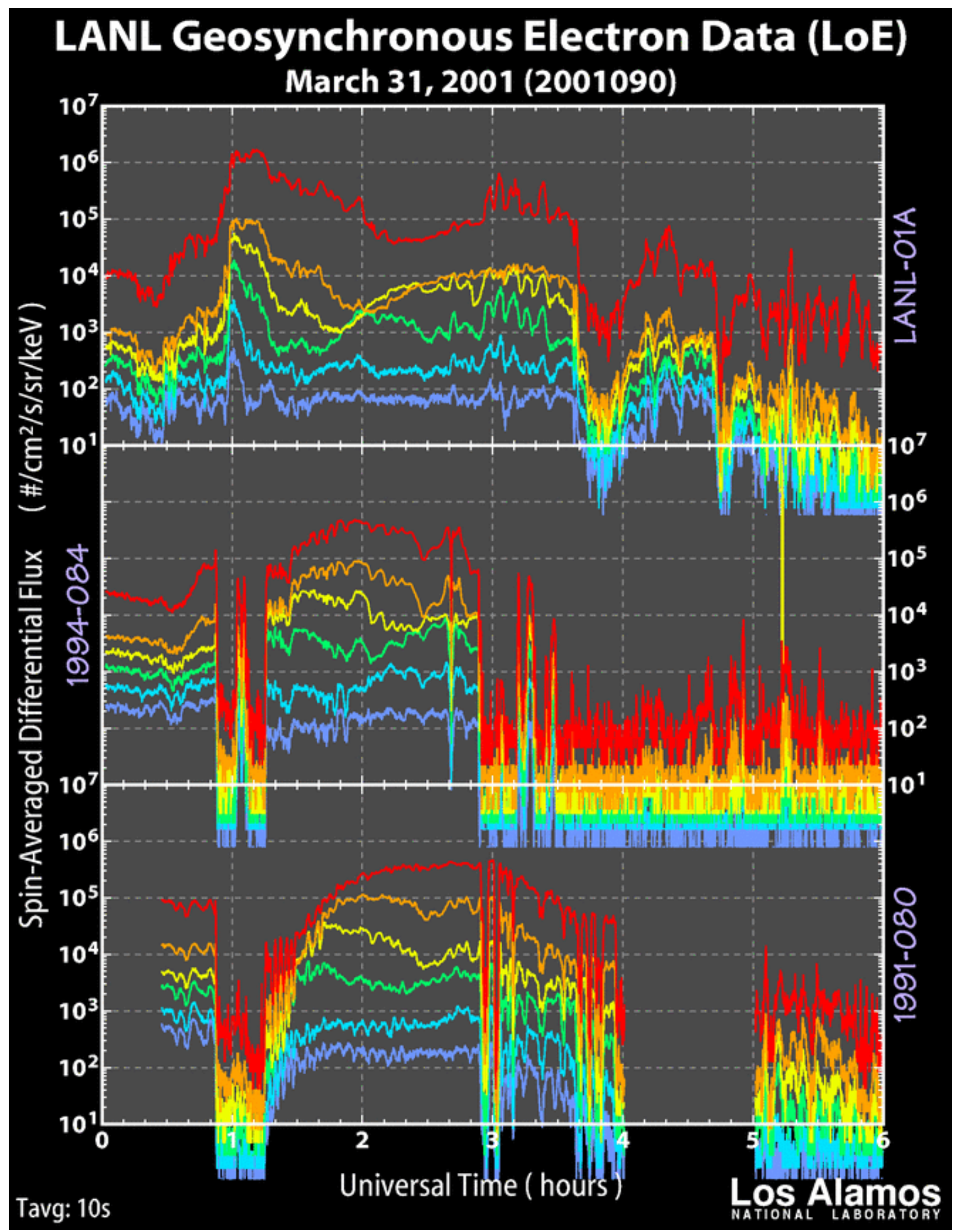

Fig. 6 - LANL Geosynchronous energetic electron data from 0000 to $060 \mathrm{UT}$. 


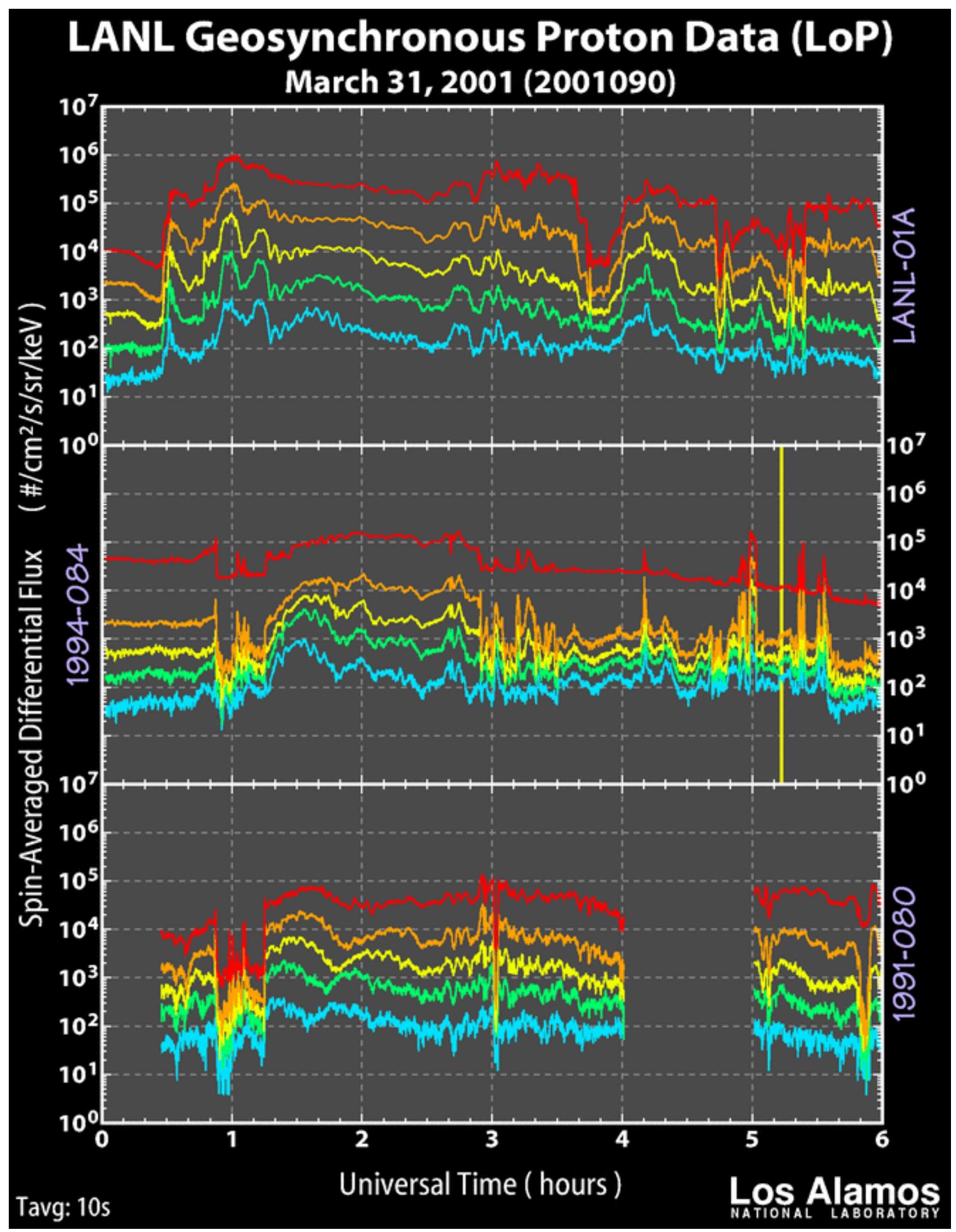

Fig. 7 - LANL Geosynchronous energetic proton data from 0000 to 060 UT. 
Magnetometer data for 2001-03-31, H component

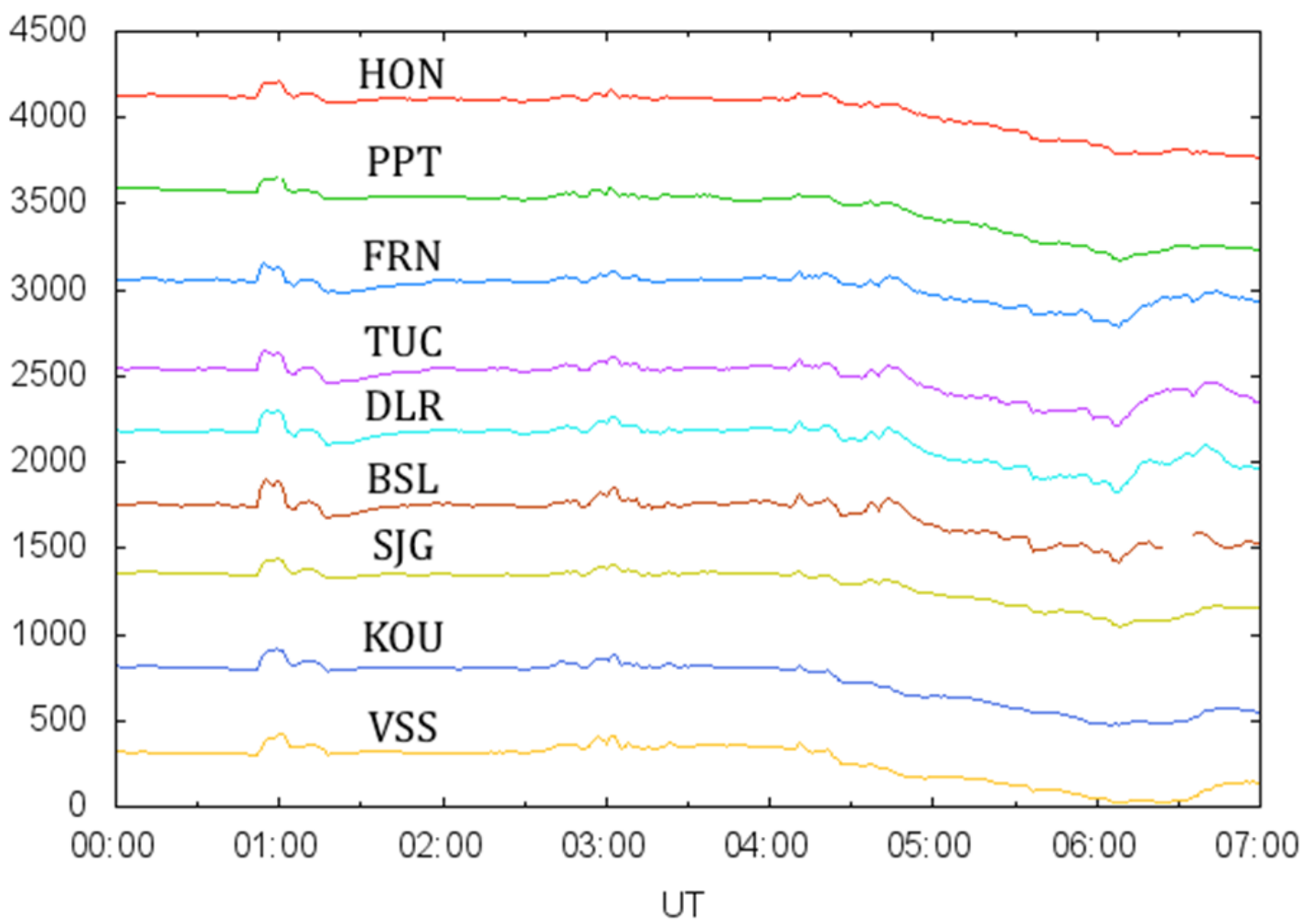

Fig. 8 - Magnetometer H-component data from mid and low latitudes on 31 March 2001. 
Magnetometer data for 2001-03-31, D component

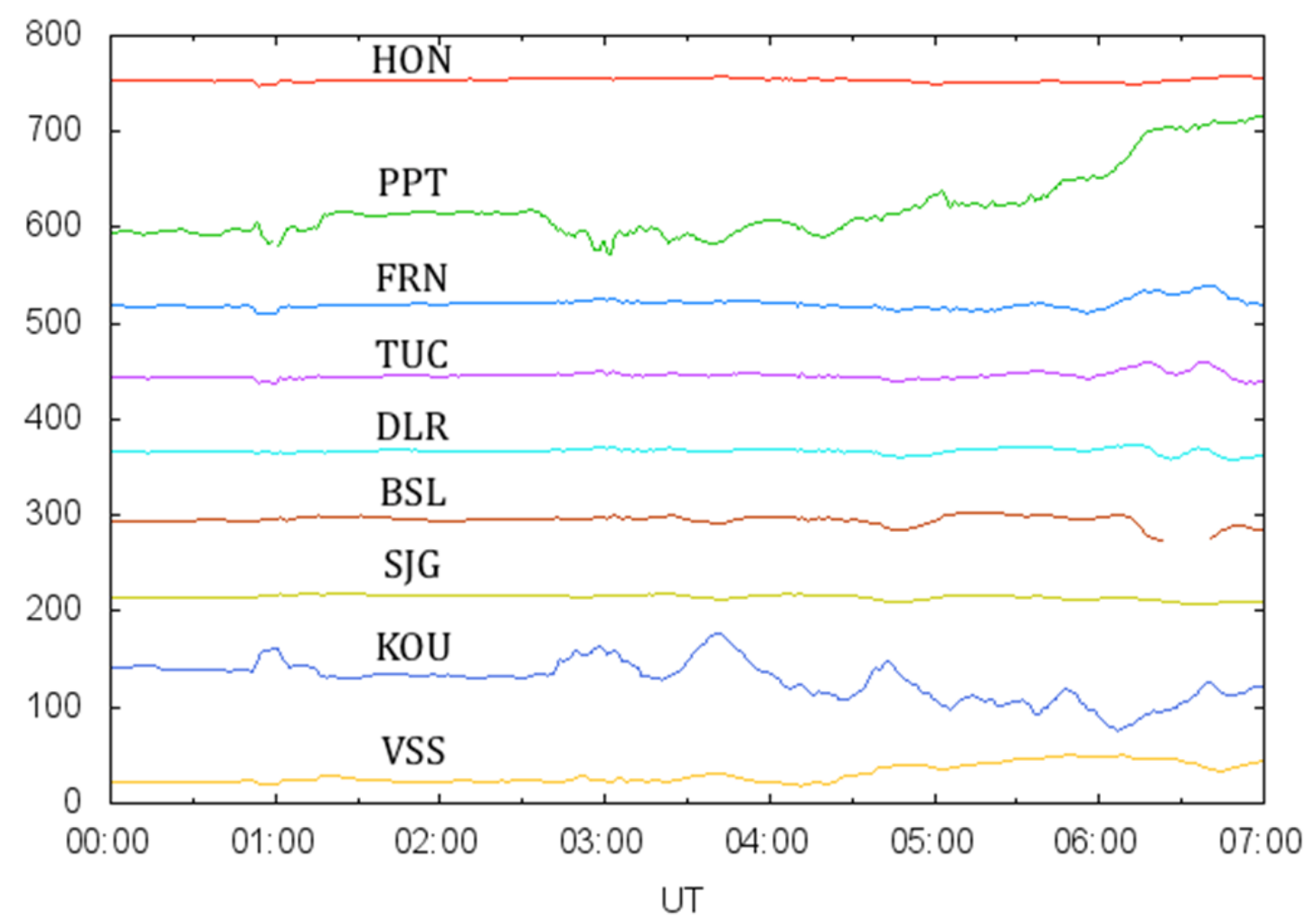

Fig. 9 - Magnetometer D-component data from mid and low latitudes on 31 March 2001. 


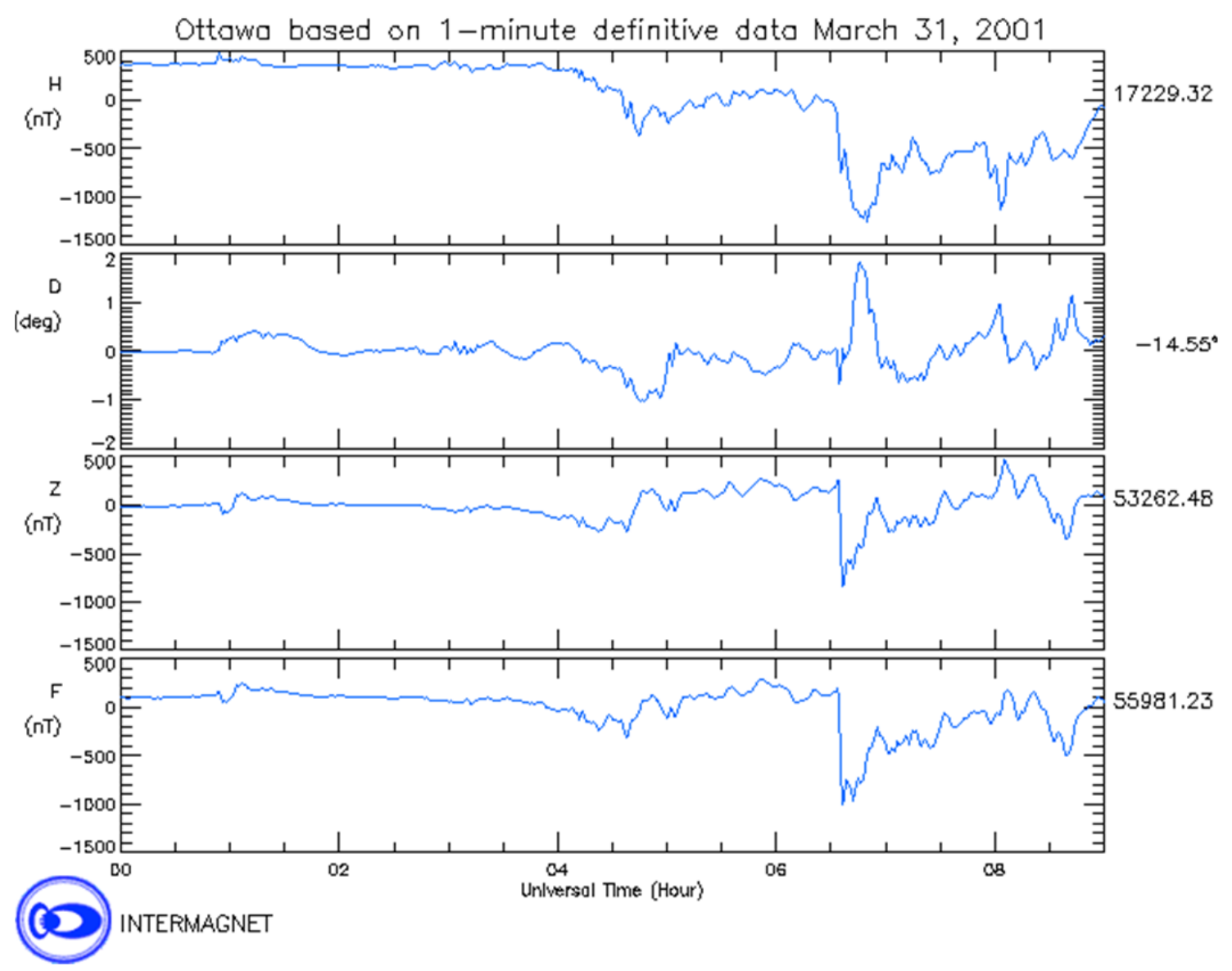

Fig. 10 - Magnetometer data from Ottowa on 31 March 2001. 
(a) 03:00 - 03:02 UTC

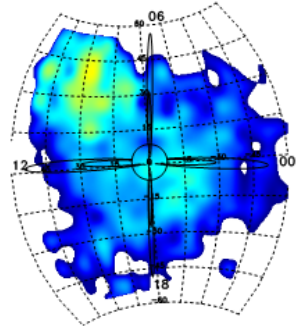

$S Y M-H=78 n T$ (b) 04:01 - 04:03 UTC

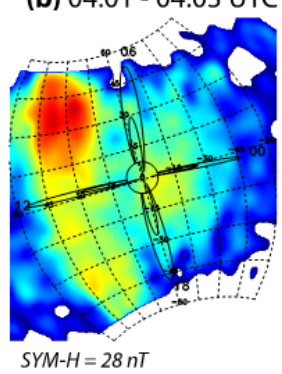

(e) 07:01 - 07:03 UTC

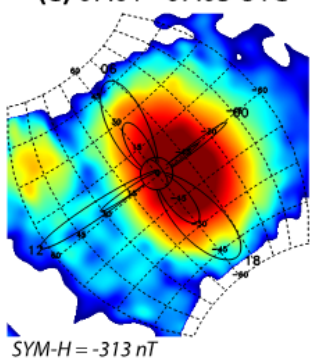

(f) 08:10 - 08:12 UTC

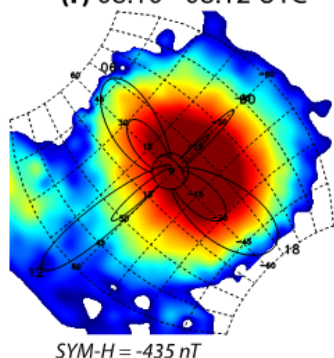

(c) 04:52 - 04:54 UTC

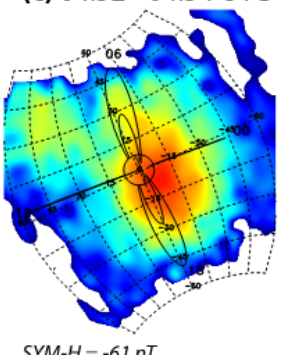

(g) 09:08 - 09:10 UTC

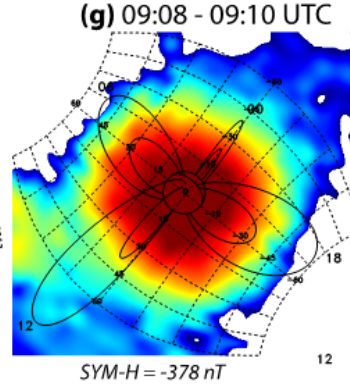

(d) 06:00 - 06:02 UTC

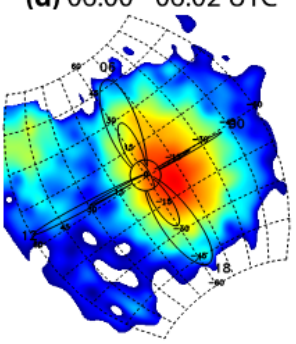

$S Y M-H=-265 n T$

(h) 10:01 - 10:03 UTC

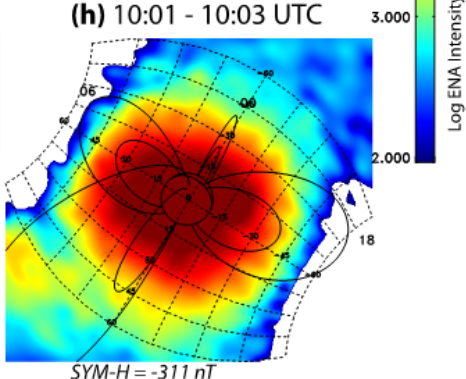

Fig. 11 - Energetic neutral observations from the HENA instrument on Image. 


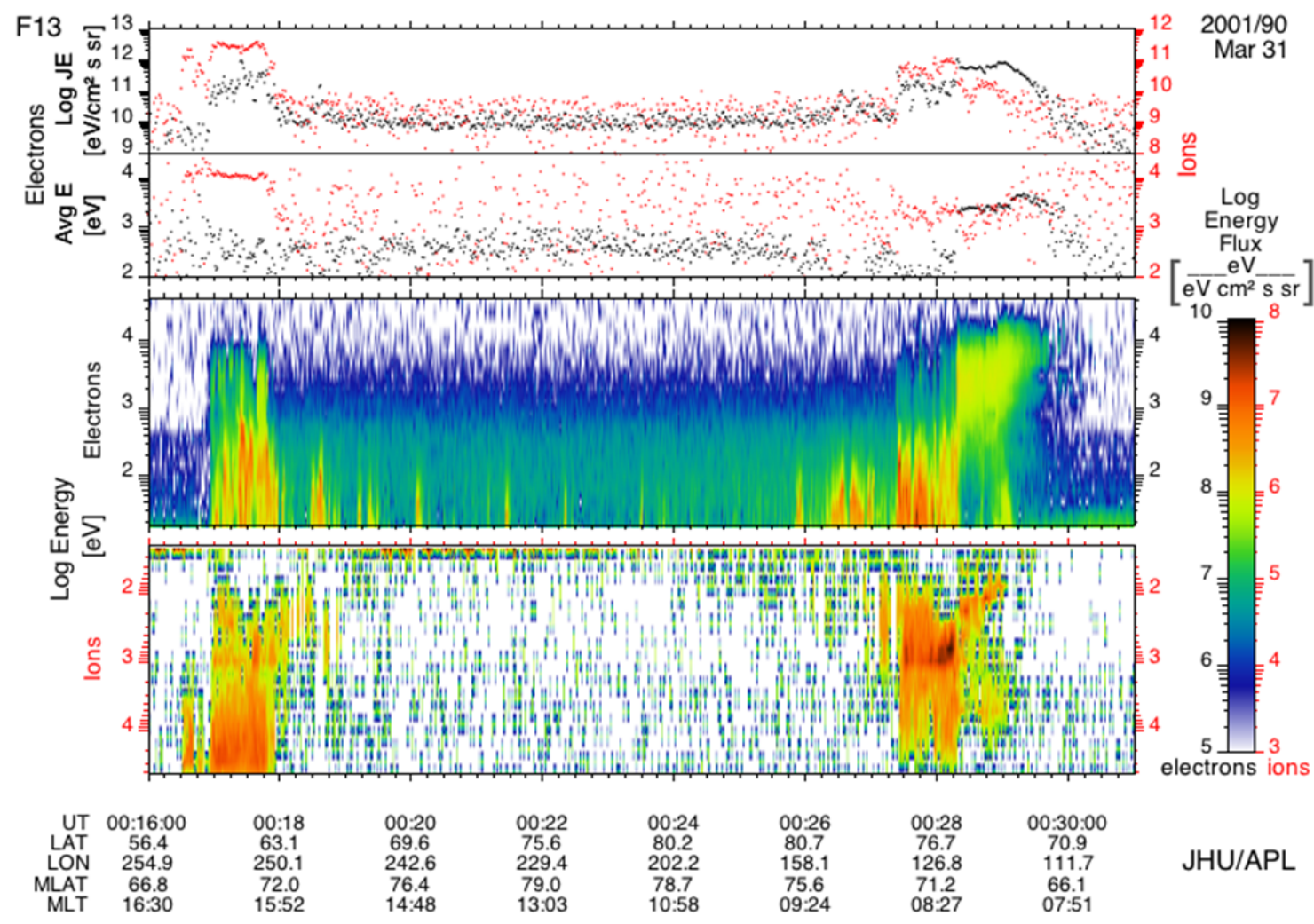

Fig. 12 - DMSP F13 particle precipitation data showing an open polar cap. 


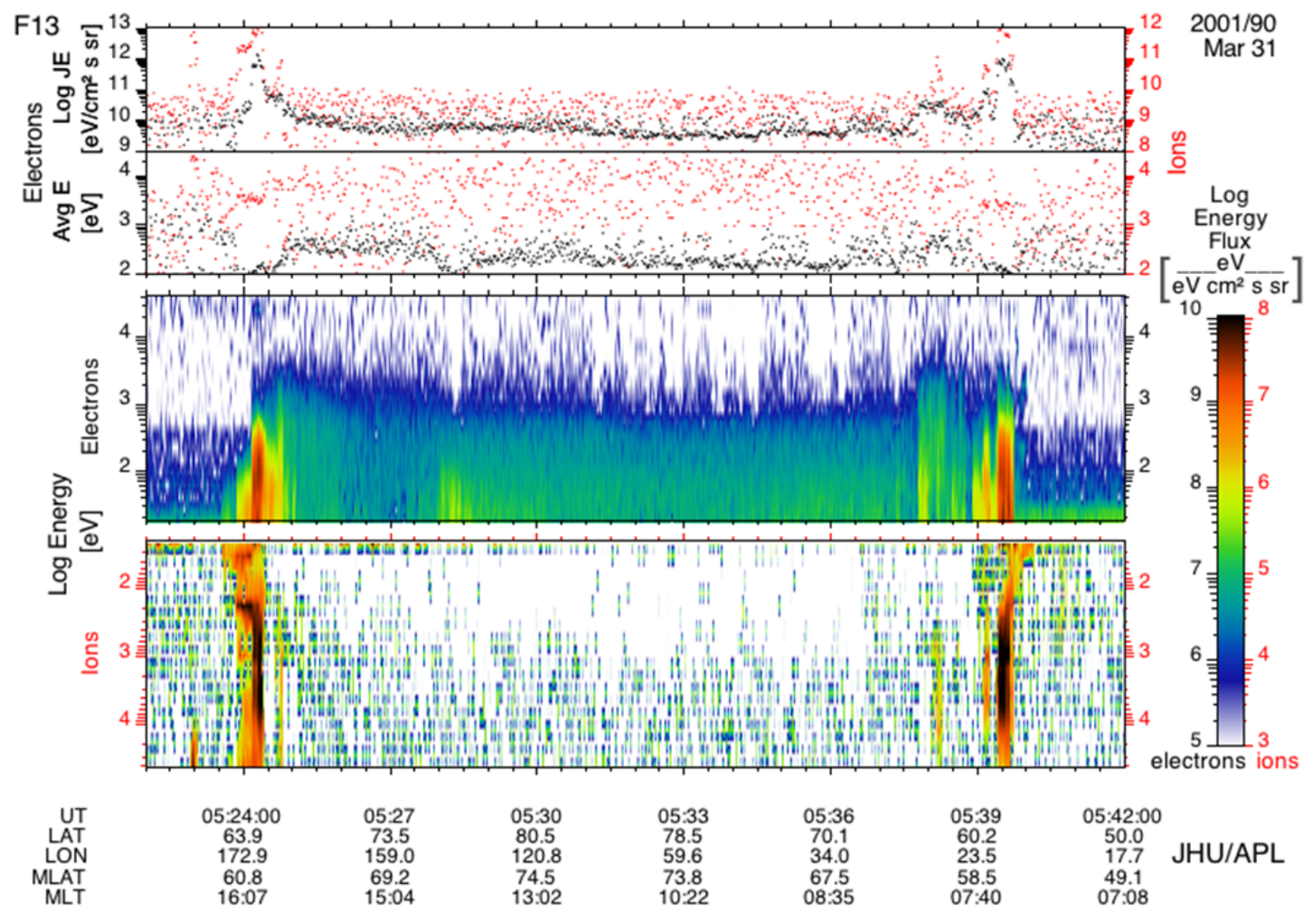

Fig. 13 - DMSP F13 particle precipitation data showing an expanded open polar cap. 


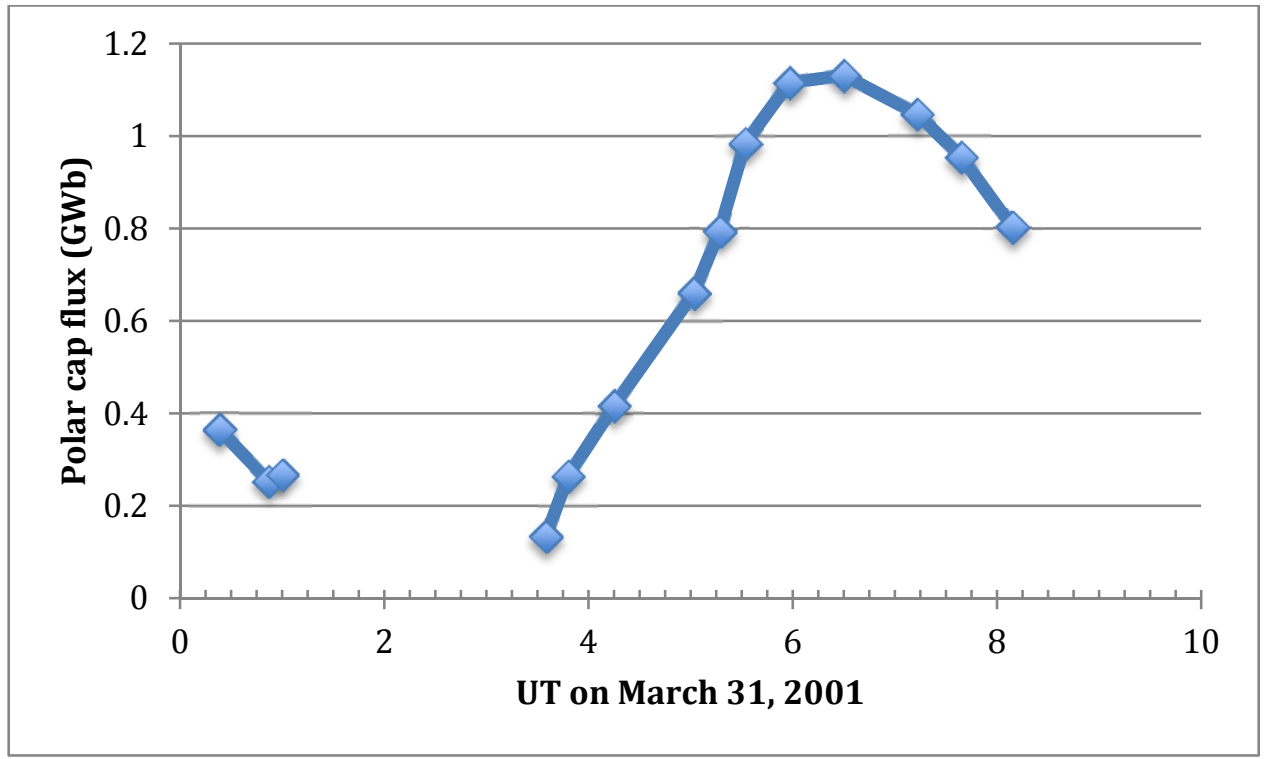

Fig. 14 - Estimated Polar Cap Flux on March 31, 2001, obtained using observations from DMSP F13, F14, and F-15 
Table 1. Magnetometer locations (stations in bold face are in the southern hemisphere)

\begin{tabular}{|l|l|l|l|}
\hline Station & Colatitude & East Longitude & LT \\
\hline HON & 68.68 & 202.0 & UT-1032 \\
\hline PPT & 107.57 & 210.42 & UT-0958 \\
\hline FRN & 52.91 & 240.28 & UT-0759 \\
\hline TUC & 57.82 & 249.27 & UT-0723 \\
\hline DLR & 60.5 & 259.08 & UT-0644 \\
\hline BSL & 59.65 & 270.36 & UT-0559 \\
\hline SJG & 71.89 & 293.85 & UT-0425 \\
\hline KOU & 84.79 & 307.27 & UT-0331 \\
\hline VSS & 112.4 & 316.35 & UT-0255 \\
\hline
\end{tabular}

